\title{
Significance of circulating microRNAs in diabetes mellitus type 2 and platelet reactivity: bioinformatic analysis and review
}

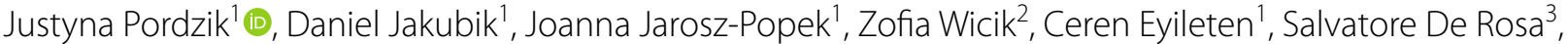 \\ Ciro Indolfi3 , Jolanta M. Siller-Matula ${ }^{4}$, Pamela Czajka ${ }^{1}$ and Marek Postula ${ }^{*}$
}

\begin{abstract}
In the light of growing global epidemic of type 2 diabetes mellitus (T2DM), significant efforts are made to discover next-generation biomarkers for early detection of the disease. Multiple mechanisms including inflammatory response, abnormal insulin secretion and glucose metabolism contribute to the development of T2DM. Platelet activation, on the other hand, is known to be one of the underlying mechanisms of atherosclerosis, which is a common T2DM complication that frequently results in ischemic events at later stages of the disease. Available data suggest that platelets contain large amounts of microRNAs (miRNAs) that are found in circulating body fluids, including the blood. Since miRNAs have been illustrated to play an important role in metabolic homeostasis through regulation of multiple genes, they attracted substantial scientific interest as diagnostic and prognostic biomarkers in T2DM. Various miRNAs, as well as their target genes are implicated in the complex pathophysiology of T2DM. This article will first review the different miRNAs studied in the context of T2DM and platelet reactivity, and subsequently present original results from bioinformatic analyses of published reports, identifying a common gene (PRKAR1A) linked to glucose metabolism, blood coagulation and insulin signalling and targeted by miRNAs in T2DM. Moreover, miRNA-target gene interaction networks built upon Gene Ontology information from electronic databases were developed. According to our results, miR-30a-5p, miR-30d-5p and miR-30c-5p are the most widely regulated miRNAs across all specified ontologies, hence they are the most promising biomarkers of T2DM to be investigated in future clinical studies.
\end{abstract}

Keywords: MicroRNA, Diabetes mellitus type 2, Platelet reactivity, Biomarker, Bioinformatic analysis, miRNA-gene target interaction, Diagnosis, Prognosis

\section{Introduction}

Type 2 diabetes mellitus (T2DM) is defined by chronic hyperglycemia and defective metabolism of carbohydrates, lipids, and proteins caused by inadequate insulin secretion and/or insulin action. The disease and its complications constitute a major health challenge. In line with the most recent reports by the International Diabetes Federation, nearly half a billion people across the globe live with diabetes, and epidemiological data predict

\footnotetext{
*Correspondence: mpostula@wum.edu.pl

${ }^{1}$ Department of Experimental and Clinical Pharmacology, Center for Preclinical Research and Technology CEPT, Medical University of Warsaw, Banacha 1B str., 02-097 Warsaw, Poland

Full list of author information is available at the end of the article
}

an unsustainable increase in its prevalence in the upcoming years [1]. The worldwide epidemic of T2DM is mainly driven by the choice of lifestyle, physical inactivity, caloric excess, obesity, as well as aging and urbanization, however genetic component is also known to be involved in its pathogenesis $[2,3]$. Furthermore, it is worth noticing that the epidemiology of diabetes has been changing over the past decades. The disease once thought to affect almost exclusively elderly population, is now often diagnosed among children and adolescents, hence placing a significant number of people at risk of developing serious complications and increasing the rates of diabetesrelated morbidity [4]. Moreover, relative mortality rates in T2DM patients are also reported to be approximately 2- to 4-times as high compared with individuals without 
T2DM, and mostly linked to an increased risk of cardiovascular disease (CVD) [5]. Thus, the rapidly increasing incidence and prevalence of T2DM raises an urgent need to develop effective tools for early detection of the disease in order to prevent the progression of T2DM and improve patients' clinical outcomes.

Platelets are thought to be important cellular components involved in both the initiation and progression of atherosclerosis, and even more so in the ensuing atherothrombotic sequelae [6]. Disturbances in the pro-inflammatory state and endothelial dysfunction observed in T2DM further contribute to the phenomenon of hypercoagulable state $[7,8]$. The interplay of impaired insulin secretion and action, inflammatory process, defective glucose metabolism and platelet activation was put at the center stage to elucidate the pathophysiology of T2DM and its most common, cardiovascular complications [8-11]. The intensified adhesion, activation, aggregation, and platelet-derived thrombin generation are typical platelet alterations in T2DM platelets [12]. Our main focus was on the increased platelet activation in diabetic populations, which was reported in the past [8]. Platelets play a significant role in coordinating inflammation and immune responses, hence their increased activity may result in ameliorated inflammatory response [13]. Moreover, platelets release microparticles (MPs), which contribute to the modulation of immune cells function [14]. These molecules were formerly thought to derive from innate immune cells, including neutrophils and monocytes, however MPs originating from platelets are the most expressed in the circulation and deemed crucial in inflammation [15]. Combining the knowledge about these mechanisms and their main molecular components is the first step in discovering and designing novel biomarkers of T2DM and impaired platelet function.

MicroRNAs (miRNAs) due to their biochemical stability and abundance in different body fluids, emerged as potential novel biomarkers for T2DM and its complications. MicroRNAs are a class of small (18-25 nucleotides), endogenous, noncoding RNAs that regulate various aspects of cellular functions through suppression of gene expression $[16,17]$. They are involved in a wide array of biological processes, such as cell development, proliferation, differentiation, as well as apoptosis or metabolism [18]. Until now, up to 2000 miRNAs have been listed for Homo sapiens, and it is estimated that the majority of protein-coding genes are directly regulated by these molecules. What is more, each miRNA can bind and regulate more than one target, exerting its effects on several levels simultaneously. Although some circulating miRNAs exhibit low expression, there is evidence of considerable redundancy among the targets. The same UTRs are targeted by numerous miRNAs thus even low expressed miRNAs exert their functions as part of an epigenetic regulation network. These miRNAs are fine-tuners of gene expression patterns in response to pathophysiological stimuli and despite being expressed at relatively low levels under basal conditions, miRNAs are strongly up-regulated during pathological stress [19]. Even though the majority of miRNAs are found intracellularly, a significant amount appears in the extracellular space, including the blood and other body fluids [20]. It is worth mentioning that platelets harbor large amounts of miRNAs. Consequently, they are the major source for circulating miRNAs, with a relevant regulatory potential on cardiovascular pathophysiology [21]. Moreover, circulating miRNAs correspond with the amount of platelet microvesicles, which are also abundantly released into circulation [21]. Thanks to their functional role and increasingly advanced detection technologies, circulating miRNAs can be extracted from plasma, serum, or whole blood, and studied in the context of becoming novel diagnostic and prognostic disease signatures.

Up to date, multiple methods were proposed and applied by researchers to detect and investigate miRNAs, including northern blotting, quantitative reverse transcription polymerase chain reaction (qRT-PCR) and microarrays. All mentioned methods have their advantages and limitations. Northern blot technology was commonly used owing to its high specificity and ability to utilize sequences with even partial homology as hybridization probes [22]. On the other hand, low detection efficiency, contamination due to radiolabeling, and poor sensitivity for oligonucleotide probes might lessen the value of northern analysis measurements [23]. Currently, qRT-PCR and microarrays are the most popular techniques for reliable and effective detection of miRNAs. While northern blot and qRT-PCR enable the analysis one by one, microarray offers to test a few hundred miRNAs per single run [24]. Along with the growing interest in miRNA use in diagnostic and therapeutic strategies, RT-PCR innovations are being proposed to enhance its efficiency. For instance, integrating with microfluidic filtering devices, as well as digital droplet PCR, are new improvements that not only offer higher analytical standards, but also require minimal reaction volumes [25]. Furthermore, next-generation sequencing (NGS) merits mention as a newly preferred technique for studying circulating miRNAs. Its main advantage is the possibility to sequence samples simultaneously by pooling with NGS and to build expression profiles for every investigated sample. The use of NGS is often limited by high cost, time consumption and staff involvement [26, 27]. Alternative techniques are also being developed, among them the use of nanosensors or nanowires, or the 
enzyme-linked assays that enable miRNAs measurement through direct hybridization [28].

Herein, we present an up-to-date review on diagnostic and prognostic value of miRNAs related to T2DM and processes potentially related to platelet reactivity based on human studies and report the results of a quantitative bioinformatic analysis highlighting the most promising miRNAs for clinical application in T2DM. Since the pathogenesis and complications of T2DM are very complex, the aim of our bioinformatic analysis was to search for common miRNAs related to processes such as glucose metabolism, inflammation or blood coagulation that can potentially be linked to platelet activation pathways. We believe that the results of our bioinformatic analysis, which revealed novel miRNA targets, could be further validated in laboratory and clinical settings and help to create a paradigm for future studies in this field.

\section{Article search process}

Electronic database Pubmed and Scopus was searched between July 2018 and November 2018, and original studies were reviewed to evaluate the potential diagnostic or/and prognostic role of circulating miRNAs associated with T2DM. Review articles and meta-analyses were also investigated, and their secondary references were examined for possible inclusion. The following search syntax was used: "Search ("MicroRNAs" [MeSH Terms] OR "mir" [MeSH Terms] OR "mirna" [MeSH Terms] OR "circulating miRNA" [MeSH Terms] OR "circulating microRNA" [MeSH Terms]) AND ("diabetes mellitus, type 2" [Mesh] [MeSH Terms] OR "T2DM" [All Fields]) AND ("diagnostic" [MeSH Terms] OR "diagnosis" [All Fields]) OR ("prognostic" [MeSH Terms] OR "prognosis" [All Fields]) AND ("blood platelets" [MeSH Terms] OR "Platelet Activation" [MeSH Terms] OR "Platelet Aggregation" [MeSH Terms] OR "Platelet reactivity" [All Fields])" Filters: Humans. Our search was limited to human studies and did not exclude studies on the basis of ethnicity of study participants. Titles and abstracts were screened by two independent operators.

\section{Circulating miRNAs and T2DM}

In light of emerging reports, differential concentration of circulating miRNAs could offer promising opportunities for diagnosis, prognosis and treatment monitoring in T2DM. The number of studies investigating the molecules' characteristics in the context of T2DM is constantly increasing, however available evidence is still limited and should be further expanded in order to elucidate the complex interactions between miRNAs and other molecules relevant in T2DM pathophysiology, as well as their potential use in clinical practice. In this section we provide a description and summary of the studies that investigated various circulating miRNAs in T2DM (see Tables 1, 2; Additional file 1).

\section{MicroRNA studies linked with glucose metabolism and development of diabetes}

The development of T2DM and resulting hyperglycemia have several underlying mechanisms. Insulin is the key hormone responsible for glucose homeostasis. T2DM subjects manifest abnormalities both in tissue sensitivity to insulin, as well as in pancreatic insulin secretion [3]. In healthy individuals, pancreatic beta cells conform to changes in insulin action, hence a potential decrease in insulin action is followed by intensified insulin secretion and vice versa. Any alteration of this dynamic interaction leads to dysfunctional glucose metabolism [3]. Whereas the studies below describe the potential relationship between miRNAs and glucose metabolism, other contributing mechanisms such as inflammation and platelet activation should be taken into account while analyzing the research outcomes.

In one of the initial studies conducted to deepen the understanding of glucose metabolism in T2DM the expression profiles of several miRNAs relevant to the pathogenesis of T2DM were investigated and compared among three subgroups of patients enrolled in the study: patients with newly diagnosed T2DM, pre-T2DM subjects and T2DM-susceptible subjects with normal glucose tolerance (NGT) [29]. The authors reported significantly higher expression of all analyzed miRNAs in T2DM patients compared to T2DM-susceptible subjects. Moreover, certain miRNAs were significantly down-regulated in the pre-T2DM individuals vs. T2DM patients. Interestingly, the expression patterns of circulating miRNAs in pre-T2DM group were similar to the ones observed in patients with NGT. On one hand, this study strengthens the hypothesis that miR-9, miR-29a, miR30d, miR-34a, miR-124a, miR146a and miR-375 may play a role in the regulation of insulin and pathogenesis of T2DM. On the other hand, their expression levels do not change dramatically in pre-T2DM stage, which undermines their usefulness as a disease-specific biomarker [29].

On the other hand, Karolina et al. aimed to identify miRNAs of patients with metabolic syndrome and compare them with subjects manifesting T2DM, among other metabolic traits. The study population comprised of five different subgroups, including metabolic syndrome subjects, T2DM subjects, hypercholesterolemic subjects, hypertensive subjects and healthy controls [30]. As far as T2DM was concerned, an association was found between miR-27a and miR-320a and metabolic syndrome. MicroRNA-150, miR-192, miR-27a, miR-320a, and miR375 were up-regulated in $\mathrm{T} 2 \mathrm{DM}$, which supports the 
Table 1 Characteristics of microRNA studies in T2DM

\begin{tabular}{|c|c|c|c|c|c|}
\hline $\begin{array}{l}\text { First author (year } \\
\text { of publication) } \\
\text { [reference] }\end{array}$ & Studied miRNAs & Expression of miRNAs & T2DM/controls & Method & Mechanism \\
\hline Kong (2011) [29] & $\begin{array}{l}\text { miR-9 } \\
\text { miR-29a } \\
\text { miR-30d } \\
\text { miR-34a } \\
\text { miR-124a } \\
\text { miR-146a } \\
\text { miR-375 }\end{array}$ & $\begin{array}{l}\uparrow \mathrm{miR}-9 \\
\uparrow \mathrm{miR}-29 \mathrm{a} \\
\uparrow \mathrm{miR}-30 \mathrm{~d} \\
\uparrow \mathrm{miR}-34 \mathrm{a} \\
\uparrow \mathrm{miR}-124 \mathrm{a} \\
\uparrow \mathrm{miR}-146 \mathrm{a} \\
\uparrow \mathrm{miR}-375\end{array}$ & $18 / 19$ & qRT-PCR & Glucose metabolism \\
\hline Karolina (2012) [30] & $\begin{array}{l}\text { miR-27a } \\
\text { miR-320a }\end{array}$ & $\begin{array}{l}\uparrow \operatorname{miR}-27 a \\
\uparrow \operatorname{miR}-320 a\end{array}$ & $50 / 46$ & $\begin{array}{l}\text { microRNA profiling } \\
\text { And qRT-PCR }\end{array}$ & Glucose metabolism \\
\hline Zhang (2013) [31] & $\begin{array}{l}\text { miR-29b } \\
\text { miR-15a } \\
\text { miR-28-3p } \\
\text { miR-223 } \\
\text { miR-126 }\end{array}$ & $\downarrow$ miR-126 & $30 / 30$ & qRT-PCR & Glucose metabolism \\
\hline Liu (2014) [32] & miR-126 & $\downarrow \mathrm{miR}-126$ & $160 / 138$ & qRT-PCR & Glucose metabolism \\
\hline Ghorbani (2017) [33] & $\begin{array}{l}\text { miR-21 } \\
\text { miR-126 } \\
\text { miR-146a }\end{array}$ & $\downarrow$ miR-21 & $45 / 42$ & qRT-PCR & Glucose metabolism \\
\hline Al-Muhtaresh (2018) [34] & $\begin{array}{l}\text { miR-375 } \\
\text { miR-9 }\end{array}$ & $\begin{array}{l}\uparrow \operatorname{miR}-375 \\
\uparrow \operatorname{miR}-9\end{array}$ & $30 / 30$ & qRT-PCR & Glucose metabolism \\
\hline Jiménez-Lucena (2018) [35] & $\begin{array}{l}\text { miR-103 } \\
\text { MiR-107 } \\
\text { miR-126 } \\
\text { miR-143 } \\
\text { miR-144 } \\
\text { miR-145 } \\
\text { miR-150 } \\
\text { miR-15a } \\
\text { miR-182 } \\
\text { miR-192 } \\
\text { miR-21 } \\
\text { miR-223 } \\
\text { miR-28-3p } \\
\text { miR-29a } \\
\text { miR-30a-5p } \\
\text { miR-30d } \\
\text { miR-320 } \\
\text { miR-33a } \\
\text { miR-375 } \\
\text { miR-657 } \\
\text { miR-7 } \\
\text { miR-9 } \\
\text { miR-96 }\end{array}$ & $\begin{array}{l}\uparrow \text { miR-30a-5p } \\
\uparrow \text { miR-150 } \\
\downarrow \text { miR-103 } \\
\downarrow \text { miR-28-3p } \\
\downarrow \text { miR-29a } \\
\downarrow \text { miR-9 } \\
\downarrow \text { miR-15a } \\
\downarrow \text { miR-126 } \\
\downarrow \text { miR-145 } \\
\downarrow \text { miR-375 } \\
\downarrow \text { miR-223 }\end{array}$ & $107 / 355$ & qRT-PCR & Glucose metabolism \\
\hline Zampetaki (2010) [36] & $\begin{array}{l}\text { miR-24 } \\
\text { miR-21 } \\
\text { miR-20b } \\
\text { miR-15a } \\
\text { miR-126 } \\
\text { miR-191 } \\
\text { miR-197 } \\
\text { miR-223 } \\
\text { miR-320 } \\
\text { miR-486 } \\
\text { miR-150 } \\
\text { miR-29b } \\
\text { miR-28-3p }\end{array}$ & $\begin{array}{l}\uparrow \mathrm{miR}-28-3 p \\
\downarrow \text { miR-24 } \\
\downarrow \text { miR-21 } \\
\downarrow \text { miR-20b } \\
\downarrow \text { miR-15a } \\
\downarrow \text { miR-126 } \\
\downarrow \text { miR-191 } \\
\downarrow \text { miR-197 } \\
\downarrow \text { miR-223 } \\
\downarrow \text { miR-320 } \\
\downarrow \text { miR-486 } \\
\downarrow \text { miR-150 } \\
\downarrow \text { miR-29b }\end{array}$ & $80 / 80$ & $\begin{array}{l}\text { microRNA profiling and } \\
\text { qRT-PCR }\end{array}$ & $\begin{array}{l}\text { miR-126: endothelial } \\
\text { dysfunction }\end{array}$ \\
\hline Zhang (2015) [37] & miR-126 & $\downarrow$ miR-126 & $20 / 20$ & qRT-PCR & Glucose metabolism \\
\hline $\begin{array}{l}\text { Balasubramanyam (2011) } \\
\text { [44] }\end{array}$ & miR-146a & $\downarrow$ miR-146a & $20 / 20$ & qRT-PCR & Inflammation \\
\hline Luo (2015) [45] & miR-103b & $\downarrow \mathrm{miR}-103 \mathrm{~b}$ & $79 / 46$ & qRT-PCR & Inflammation \\
\hline
\end{tabular}


Table 1 (continued)

\begin{tabular}{|c|c|c|c|c|c|}
\hline $\begin{array}{l}\text { First author (year } \\
\text { of publication) } \\
\text { [reference] }\end{array}$ & Studied miRNAs & Expression of miRNAs & T2DM/controls & Method & Mechanism \\
\hline Olivieri (2015) [47] & $\begin{array}{l}\text { miR-126-3p } \\
\text { miR-21-5p }\end{array}$ & $\begin{array}{l}\downarrow \text { miR-126-3p } \\
\downarrow \text { miR-21-5p }\end{array}$ & 193/107 & qRT-PCR & Inflammation \\
\hline Giannella (2017) [48] & $\begin{array}{l}\text { miR-126-3p } \\
\text { miR-126-5p }\end{array}$ & $\downarrow$ miR-126-3p & $68 / 53$ & qRT-PCR & Inflammation \\
\hline Witkowski [49] & miR-126 & $\downarrow$ miR-126 & $46 /-$ & QRT-PCR & Inflammation \\
\hline Jansen (2016) [54] & $\begin{array}{l}\text { miR-126 } \\
\text { miR-222 } \\
\text { miR-let7d } \\
\text { miR-21 } \\
\text { miR-30 } \\
\text { miR-92a } \\
\text { miR-139 } \\
\text { miR-199a } \\
\text { MiR-26a }\end{array}$ & $\begin{array}{l}\downarrow \text { miR-126 } \\
\downarrow \text { miR-26a }\end{array}$ & $55 / 80$ & qRT-PCR & Endothelial dysfunction \\
\hline Deng (2017) [55] & miR-24 & $\downarrow$ miR-24 & $28 / 31$ & qRT-PCR & Endothelial dysfunction \\
\hline Amr (2018) [56] & $\begin{array}{l}\text { miR-126 } \\
\text { MiR-210 }\end{array}$ & $\begin{array}{l}\downarrow \mathrm{miR}-126 \\
\uparrow \mathrm{miR}-210\end{array}$ & $100 / 20$ & qRT-PCR & $\begin{array}{l}\text { miR-126: Endothelial } \\
\text { dysfunction miR-2010 } \\
\text { hypoxia }\end{array}$ \\
\hline Stępień (2018) [57] & $\begin{array}{l}\text { miR-126-3p } \\
\text { miR-126-5p } \\
\text { miR-193b-3p } \\
\text { miR-199a-3p } \\
\text { miR-20a-3p } \\
\text { miR-221-3p } \\
\text { miR-23b-3p } \\
\text { miR-26a-5p } \\
\text { miR-26b-5p } \\
\text { miR-29a-5p } \\
\text { MiR-30b-5p } \\
\text { miR-30c-5p } \\
\text { miR-374a-5p } \\
\text { miR-409-3p } \\
\text { miR-495-3p } \\
\text { miR-95-3p } \\
\text { let-7i-5p }\end{array}$ & $\begin{array}{l}\uparrow \text { miR-193b-3p } \\
\uparrow \text { let-7i-5p } \\
\uparrow \text { miR-199a-3-5p } \\
\uparrow \text { miR-26b-5p } \\
\uparrow \text { miR-30b-5p } \\
\uparrow \text { miR-374a-5p } \\
\uparrow \text { miR-20a-3p } \\
\uparrow \text { miR-26a-5p } \\
\uparrow \text { miR-30c-5p } \\
\downarrow \text { miR-409-3p } \\
\downarrow \text { miR-95-3p }\end{array}$ & $15 / 15$ & $\begin{array}{l}\text { microRNA profiling and } \\
\text { qRT-PCR }\end{array}$ & Angiogenesis \\
\hline Stratz (2014) [59] & $\begin{array}{l}\operatorname{miR}-377-5 p \\
\text { miR-628-3p } \\
\text { miR-3137 }\end{array}$ & $\begin{array}{l}\text { No significant differ- } \\
\text { ences in platelet miRNA } \\
\text { profiles }\end{array}$ & $30 / 30$ & $\begin{array}{l}\text { microRNA profiling and } \\
\text { qRT-PCR }\end{array}$ & Platelet reactivity \\
\hline Fejes (2017) [60] & $\begin{array}{l}\text { miR-223 } \\
\text { miR-26b } \\
\text { miR-126 } \\
\text { MiR-140 }\end{array}$ & $\begin{array}{l}\downarrow \text { miR-223 } \\
\downarrow \text { miR-26b } \\
\downarrow \text { miR-126 } \\
\downarrow \text { miR-140 }\end{array}$ & $28 / 23$ & qRT-PCR & Platelet reactivity \\
\hline
\end{tabular}

hypothesis that they might be involved in the regulation of hyperglycemia and should be investigated in greater depth. The current findings indicate a potential clinical use of these miRNAs in estimation of risk of T2DM and metabolic syndrome [30].

Also, Zhang et al. [31] conducted a cross-sectional study to investigate the miRNA profile among individuals with appropriate glycemia, individuals susceptible of developing T2DM and T2DM patients, and aimed to estimate their predictive value. The expression of several circulating miRNAs was compared between the different groups, however only miR-15a, miR-223 and miR-126 were detectable in plasma. Interestingly, plasma miR-126 levels were analogous between pre-T2DM and T2DM groups, yet substantially lower than in NGT group. Furthermore, the expression pattern of plasma miR-126 was linked with fasting glucose levels. The study revealed that both detection and estimation of plasma miR-126 level could be potentially considered as a non-invasive diagnostic tool to predict and prevent T2DM [31].

The use of differential expression of circulating miR126 as potential biomarker of pre-T2DM and T2DM was further investigated by Liu et al. [32]. The analysis was performed among impaired glucose tolerance (IGT) 
Table 2 Expression and statistical analysis results of microRNAs studied in T2DM

\begin{tabular}{|c|c|c|c|c|c|}
\hline \multirow[t]{2}{*}{ First author [reference] } & \multirow[t]{2}{*}{ Expression of miRNA } & \multirow[t]{2}{*}{ OR } & \multirow[t]{2}{*}{$p$ value } & \multicolumn{2}{|l|}{ AUC } \\
\hline & & & & Sensitivity & Specificity \\
\hline \multirow[t]{7}{*}{ Kong (2011) [29] } & \multirow{7}{*}{$\begin{array}{l}\uparrow \mathrm{miR}-9 \\
\uparrow \mathrm{miR}-29 \mathrm{a} \\
\uparrow \mathrm{miR}-30 \mathrm{~d} \\
\uparrow \mathrm{miR} 34 \mathrm{a} \\
\uparrow \mathrm{miR}-124 \mathrm{a} \\
\uparrow \mathrm{miR} 146 \mathrm{a} \\
\uparrow \mathrm{miR}-375\end{array}$} & & 0.021 & \multirow[t]{7}{*}{-} & \multirow[t]{7}{*}{-} \\
\hline & & & 0.003 & & \\
\hline & & & 0.12 & & \\
\hline & & & 0.001 & & \\
\hline & & & 0.12 & & \\
\hline & & & 0.01 & & \\
\hline & & & 0.002 & & \\
\hline Karolina (2012) [30] & $\begin{array}{l}\uparrow \mathrm{miR}-27 \mathrm{a} \\
\uparrow \mathrm{miR}-320 \mathrm{a}\end{array}$ & - & $\begin{array}{l}0.010 \\
0.019\end{array}$ & - & - \\
\hline Zhang (2013) [31] & $\downarrow$ miR-126 & - & $<0.01$ & - & - \\
\hline Liu (2014) [32] & $\downarrow$ miR-126 & 3.5 & $<0.05$ & 0.792 & - \\
\hline Ghorbani (2017) [33] & $\downarrow \mathrm{miR}-21$ & - & $0.01 / 0.03$ & - & - \\
\hline Al-Muhtaresh (2018) [34] & $\begin{array}{l}\uparrow \operatorname{miR}-375 \\
\uparrow \mathrm{miR}-9\end{array}$ & $\begin{array}{l}1.12-1.151 \\
0.972-1.006\end{array}$ & $\begin{array}{l}0.001-0.05 \\
0.33-0.954\end{array}$ & $\begin{array}{l}0.78 \\
0.532\end{array}$ & - \\
\hline Jiménez-Lucena (2018) [35] & $\begin{array}{l}\uparrow \text { miR-30a-5p } \\
\uparrow \text { miR-150 } \\
\downarrow \text { miR-103 } \\
\downarrow \text { miR-28-3p } \\
\downarrow \text { miR-29a } \\
\downarrow \text { miR-9 }\end{array}$ & - & $\begin{array}{l}<0.001 \\
<0.001 \\
<0.001 \\
<0.001 \\
<0.001 \\
<0.001\end{array}$ & - & - \\
\hline Zampetaki (2010) [36] & $\begin{array}{l}\uparrow \text { miR-28-3p } \\
\downarrow \text { miR-24 } \\
\downarrow \text { miR-21 } \\
\downarrow \text { miR-20b } \\
\downarrow \text { miR-15a } \\
\downarrow \text { miR-126 } \\
\downarrow \text { miR-191 } \\
\downarrow \text { miR-197 } \\
\downarrow \text { miR-223 } \\
\downarrow \text { miR-320 } \\
\downarrow \text { miR-486 } \\
\downarrow \text { miR-150 } \\
\downarrow \text { miR-29b }\end{array}$ & - & - & - & - \\
\hline Zhang (2015) [37] & $\downarrow$ miR-126 & 0.967 & 0.0158 & 0.7778 & 0.6667 \\
\hline Balasubramanyam (2011) [44] & $\downarrow \mathrm{miR}-146 \mathrm{a}$ & - & 0.015 & - & - \\
\hline Luo (2015) [45] & $\downarrow$ miR-103b & - & $<0.05$ & - & - \\
\hline Olivieri (2015) [47] & $\begin{array}{l}\downarrow \text { miR-126-3p } \\
\downarrow \text { miR-21-5p }\end{array}$ & - & $\begin{array}{l}0.032 \\
<0.001\end{array}$ & - & - \\
\hline Giannella (2017) [48] & $\downarrow$ miR-126-3p & - & $0.001,<0.001$ & - & - \\
\hline Witkowski [49] & $\downarrow \mathrm{miR}-126$ & - & 0.226 & - & - \\
\hline Jansen [54] & $\begin{array}{l}\downarrow \text { miR-126 } \\
\downarrow \text { miR-26a }\end{array}$ & - & $\begin{array}{l}0.226 \\
0.0094\end{array}$ & - & - \\
\hline Deng (2017) [55] & $\downarrow$ miR-24 & - & $<0.01$ & 0.975 & \\
\hline Amr (2018) [56] & $\begin{array}{l}\downarrow \text { miR-126 } \\
\uparrow \text { miR-210 }\end{array}$ & & $\begin{array}{l}<0.01 \\
<0.01\end{array}$ & $\begin{array}{l}0.96-0.98 \\
0.95-0.98\end{array}$ & - \\
\hline Stępień (2018) [57] & $\begin{array}{l}\uparrow \text { miR-193b-3p } \\
\uparrow \text { let-7i-5p } \\
\uparrow \text { miR-199a-3-5p } \\
\uparrow \text { miR-26b-5p } \\
\uparrow \text { miR-30b-5p } \\
\uparrow \text { miR-374a-5p } \\
\uparrow \text { miR-20a-3p } \\
\uparrow \text { miR-26a-5p } \\
\uparrow \text { miR-30c-5p } \\
\downarrow \text { miR-409-3p } \\
\downarrow \text { miR-95-3p }\end{array}$ & - & $\begin{array}{l}0.015 \\
0.006 \\
0.001 \\
0.012 \\
0.01 \\
0.00001 \\
0.064 \\
0.075 \\
0.055 \\
0.004 \\
0.041\end{array}$ & - & - \\
\hline
\end{tabular}


Table 2 (continued)

\begin{tabular}{|c|c|c|c|c|c|}
\hline \multirow[t]{2}{*}{ First author [reference] } & \multirow[t]{2}{*}{ Expression of miRNA } & \multirow[t]{2}{*}{ OR } & \multirow[t]{2}{*}{$p$ value } & \multicolumn{2}{|l|}{ AUC } \\
\hline & & & & Sensitivity & Specificity \\
\hline Stratz (2014) [59] & $\begin{array}{l}\text { No significant differences in } \\
\text { platelet miRNA profiles }\end{array}$ & & & & \\
\hline Fejes (2017) [60] & $\begin{array}{l}\downarrow \text { miR-223 } \\
\downarrow \text { miR-26b } \\
\downarrow \text { miR-126 } \\
\downarrow \text { miR-140 }\end{array}$ & - & $\begin{array}{l}<0.01 / 0.382 \\
<0.01 / 0.011 \\
- \\
-\end{array}$ & - & - \\
\hline
\end{tabular}

subjects, impaired fasting glucose (IFG) subjects, recently diagnosed T2DM patients as well as healthy individuals, and demonstrated that substantially lower values of miR-126 characterized T2DM and impaired IGT/IFG subjects in comparison to healthy individuals. Additionally, receiver operator characteristic (ROC) analysis of serum miR-126 allowed to differentiate T2DM/IFG/IGT patients from control subjects. The study was not only extended to include pre-T2DM patients but also evaluated a potential therapeutic response value of miR-126. It was reported that serum miR-126 increased after 6 months of diet control and physical exercise in IGT/ IFG subjects, as well as 6 months of diet control, exercise and insulin treatment in T2DM patients. The findings show the likely use of miR-126 to both effectively diagnose T2DM at early stages and monitor the therapeutic response [32].

Furthermore, serum miRNAs were recently evaluated in T2DM patients and control subjects in order to find the potential relationship between these miRNAs, obesity and T2DM [33]. In contrast to previous reports, no significant difference in the expression of the abovementioned miRNAs was observed between the studied cohorts. Although miR-21 was significantly down-regulated in both obese T2DM, as well as obese non-T2DM patients compared to lean individuals, miR-126 and miR146a did not correlate with biochemical parameters in the patient and control groups. The study demonstrates that serum miR-21 expression does not correlate with T2DM, nonetheless it correlates negatively with obesity in both T2DM and non-T2DM groups. Additionally, miR-21 level is linked with clinical and biochemical metabolic patterns characteristic for obesity, namely BMI and waist circumference, in the evaluated cohorts [33].

The diagnostic value of miR-375 and miR-9, known to influence the regulation of insulin secretion, was investigated in early detection of pre-T2DM states and T2DM among three different cohorts consisting of preT2DM patients, T2DM patients and controls [34]. The expression of both circulating miRNAs was elevated in pre-T2DM and T2DM groups compared to controls. Furthermore, miR-375 and miR-9 were found to be directly linked to the presence of pre-T2DM and T2DM independently of risk factors, whereas miR-375 was independently associated with the development of T2DM. In line with ROC analysis results, miR-375 is suitable for differentiating T2DM patients from healthy individuals, as well as pre-T2DM from T2DM subjects, although miR-9 offers borderline significance in differentiating the patient cohorts. It is worth noticing that it is the combination of both miRNAs that showed improved predictability to discriminate the patients with inappropriate glycemia from control subjects. The findings indicate that miR-375 and miR-9 correlate with the susceptibility to developing T2DM and should be further studied to confirm their potential biomarker characteristics [34].

More recently, Jiménez-Lucena et al. [35] analyzed plasma miRNAs related to insulin sensitivity, secretion and growth among subjects with incidentally developed T2DM and non-T2DM controls. As far as baseline plasma levels were concerned, nine miRNAs (miR-9, miR-15a, miR-28-3p, miR-29a, miR-103, miR223, miR-126, miR-145, and miR-375) were significantly down-regulated, whereas two miRNAs (miR-30a-5p and miR-150) were significantly up-regulated in incident-T2DM vs. non-T2DM subjects. In line with the ROC analysis results, miR-9, miR-28-3p, miR-29a, miR30a-5p, miR-103, miR-126, miR-150, miR-223, and miR-375, combined with glycated hemoglobin (HbA1c), have a higher diagnostic value in T2DM than HbA1c alone. Finally, Cox regression analysis demonstrated that patients with down-regulated miR-103, miR-28-3p, miR29a, and miR-9 and up-regulated miR-30a-5p and miR150 are more likely to develop T2DM. To conclude, the findings support the hypothesis that miRNAs could serve as a diagnostic tool to predict the development of T2DM [35].

In one of the prospective studies using microarray methodology the potential utility of miRNAs as diagnostic biomarkers was evaluated in T2DM patients and matching controls [36]. It was revealed that miR-20b, miR-21, miR-24, miR-15a, miR-126, miR-191, miR-197, miR-223 and miR-320 were down-regulated, whereas miR-486 and miR-28-3p were up-regulated in prevalent 
T2DM. On the other hand, down-regulation of miR15a, miR-29b, miR-126, miR-223, and up-regulation of miR-28-3p negatively correlated with the manifestation of T2DM. Interestingly, miR-126 emerged as a dynamic and significant diagnostic tool of manifest T2DM, hence its expression was evaluated in the entire Bruneck cohort and assessed in both univariate and multivariate analyses. The authors further reported that the content of miR-126 in apoptotic bodies of exosomes and circulating vesicles in plasma is diminished in high glycemia. Overall, Zampetaki et al. [36] presented a miRNA profile characteristic for T2DM, which partially explains the change in angiogenic status among these patients.

The diagnostic role of miR-126 in predicting the onset of T2DM was reported in another prospective study conducted in groups of T2DM patients and healthy controls, whose authors found that the baseline levels of miR-126 were substantially lower among subjects who developed T2DM in 2 years compared to individuals with NGT [37]. The results revealed that miR-126 might correlate with onset of T2DM, and if more investigations on larger populations confirm these findings, this miRNA could be applied as a tool to detect the T2DM before its clinical manifestations emerge [37].

The studies described above suggest that miRNAs are differentially expressed among T2DM-susceptible subjects, T2DM patients and healthy individuals and indeed have a diagnostic potential. Glucose metabolism dysfunction has a significant impact on other cells, tissues and processes, which altogether give rise to T2DM. However, identifying the various molecules which take part in individual pathways, might aid in designing new diagnostic tools. As observed, miR-126 and miR-375 are among the most commonly reported miRNAs in these studies, hence efforts should be made to elucidate their role in T2DM pathogenesis and potential use in diagnostic and therapeutic strategies. It is worth noticing that the study by Zampetaki et al., as well as by Zhang et al. provided prospective data in terms of biomarker potential of microRNAs for the onset of T2DM, in contrast to other cross-sectional studies, which have numerous limitations [36, 37]. Cross-sectional data fail to accurately establish causal order, in particular at the level of an individual, and cannot be used to analyze the variations of miRNA expression over a period of time. These types of bias are essential to consider while analyzing the studies.

\section{MicroRNA studies linked with inflammation}

Evidence linking systemic inflammation to T2DM has been continuously accumulating. Whereas the triggering mechanisms of inflammation in T2DM pathogenesis are still ill-understood, the implications of chronic activation of proinflammatory pathways in target cells of insulin action likely contribute to various metabolic disorders, including T2DM. The relationship is further strengthened by the presence of key inflammatory biomarkers, such as leptin, tumor necrosis factors (TNFs), interleukin-6 (IL-6), C-C motif chemokine 2, resistin or adiponectin, in the event of T2DM and complications [12, 38-40]. Moreover, it was reported that platelet hyperreactivity in T2DM can occur in response to systemic inflammation, as evidenced by the increased expression of platelet FcgammaRIIA receptor, an immunoreceptor on the platelet surface that has been shown to activate platelets through a common signaling pathway that includes the tyrosine kinase Syk and phospholipase C 2 [41-43]. Higher expression of platelet FcgammaRIIA is observed in patients with T2DM, as well as acute coronary or cerebrovascular events, among others. These findings led to speculations that increased platelet FcgammaRIIA predisposes to occurrence of atherothrombotic events [43]. Since inflammation and platelet reactivity are largely intertwined, the studies presented below could share elements of both mechanisms.

The role of miR-146a expression along with its downstream proinflammatory signals in relation to glycemia and insulin resistance was evaluated by Balasubramanyam et al. [44] in patients with T2DM and compared to NGT controls. In line with obtained results, the expression level of miR-146a was significantly decreased in T2DM patients vs. control subjects. Furthermore, the authors studied the expression of two confirmed gene targets of miR-146a, namely TRAF6 and IRAK1 along with nuclear factor $\kappa \mathrm{B}(\mathrm{NF} \kappa \beta)$ messenger RNA (mRNA) levels and found that the TRAF6 expression was significantly increased in patients with T2DM compared to controls, whereas no significant difference was seen in the expression of $N F K \beta$ and IRAK1. The findings revealed that miR-146a expression negatively correlated with fasting blood glucose (FBG), HbA1c, insulin resistance, proinflammatory signals such as TRAF6 and NFK $\beta$ mRNA levels and also concentration of proinflammatory cytokines TNF $\alpha$ and IL- 6 . Overall, it was reported that an impairment and down-regulation of miR-146a correlates with inflammatory changes and insulin resistance observed in T2DM [44].

Moreover, the expression profile of platelet-derived miR-103b, a regulator of secreted frizzled-related protein 4 (SFRP4), was studied to determine whether miR-103b can be used as a potential biomarker for early detection of T2DM [45]. Four groups of participants were evaluated in the study, namely healthy subjects, pre-T2DM subjects, non-complicated T2DM subjects and T2DMcoronary heart disease (CHD) subjects. The correlation between miR-103b levels and its target gene SFRP4 expression was also investigated. The SFRP4 is involved 
in inflammatory processes and was formerly found to be over-expressed in the pancreatic islets of T2DM patients, suggesting its promising use as a biomarker of T2DM [46]. The results showed that miR-103b expression was significantly decreased in pre-T2DM compared to the control subjects, whereas the expression of the SFRP4 gene was increased in platelets and pre-T2DM subjects. Interestingly, platelet-derived miR-103b was down-regulated and SFRP4 up-regulated in patients subjected to antiplatelet treatment with acetylsalicylic acid, adding a potential therapeutic response value to its use as a biomarker. In line with these findings, miR-103b might have a negative regulatory function in the expression of SFRP4 mRNA/protein in pre-T2DM, and hence correlate with the early development of T2DM [45].

MicroRNAs linked to endothelial function and inflammatory processes in T2DM, miR-126-3p and miR-21-5p respectively, were also evaluated among four different groups of patients-healthy controls, T2DM subjects, T2DM subjects without (T2DM NC) and with (T2DM C) complications [46]. The expression of miR-126-3p and miR-21-5p decreased significantly from controls to T2DM NC and T2DM C, nevertheless the differences in miRNA expression were not significant between patients without and with T2DM complications. It is worth mentioning that out of all studied T2DM complications, the levels of both miRNAs differed significantly only between T2DM subjects with and without the history of major cardiovascular events (MACE). In line with multivariate analysis results, miR-21-5p and miR-126-3p were esteemed significant variables in the development of MACE complications. Overall, both miR-21-5p and miR126-3p were found to contribute to the inflammatory and endothelial dysfunction in T2DM patients, predicting their future use in estimating the risk of occurrence of T2DM complications [47]. It merits special mention that inflammation and increased platelet activation are closely linked to each other and contribute to endothelial dysfunction, as well as resulting vascular changes in T2DM.

Recently, the level of circulating MPs, their content of miR-126-3p and miR-126-5p and association with endothelial activation and dysfunction was studied in patients with various levels of inappropriate glycemia [48]. Subjects with IGT, T2DM patients and healthy controls were included in the study. Firstly, the authors noticed that only $\mathrm{CD} 6 \mathrm{E}^{+}$MPs was significantly higher among pre-T2DM and T2DM patients in comparison to glucose tolerant individuals. Multiple linear analysis demonstrated that only plasma glucose degree was the most independent forecaster of $\mathrm{CD}_{2} \mathrm{E}^{+}$. Moreover, miR-126-3p was shown to be was substantially higher in MPs among healthy individuals in contrast to comparable expression between patients with pre-T2DM and
T2DM, and no significant correlation was found between miR-126-5p and the rest of subjects. Overall, the levels of circulating CD62 $\mathrm{E}^{+}$MPs and miR-126-3p contained in MPs are different in subjects with various level of glycemia and miR-126-3p value is associated with generally approved endothelial dysfunction markers such as vascular cell adhesion protein-1 (VCAM-1), plasma antioxidant level and MPs [48].

Interestingly, miR-126 level was also shown to correlate with therapeutic response in T2DM, hence it is vital to consider antidiabetic treatment while interpreting its expression profiles. Up-regulation of miR-126 in the circumstances of uncontrolled T2DM was found by Witkowski et al. [49], who evaluated the contribution of miRNA to circulating tissue factor (TF) expression and thrombogenicity in T2DM patients before and after optimization of antidiabetic treatment. They reported that low miR-126 was linked to increased TF, TF-mediated thrombogenicity, as well as increased vascular inflammation. Furthermore, miR-126 levels increased and thrombogenicity was reduced once antidiabetic treatment had been optimized, hence suggesting the antithrombotic properties of miR-126. The studies by Witkowski et al., as well as by Liu et al., show that miR-126 levels might be restored by effective antidiabetic treatment and dietary interventions, and be applied as a marker of therapeutic response [32, 49]. The study also reflects the regulation pattern characteristic for miR-126, which appears to be one of the main miRNAs responding to diabetic environment. It was found that the expression of miR-126 is regulated by transcription factors Ets-1 and Ets-2 [50]. Witkowski et al. reported that high-glucose treatment of endothelial cells decreased ets-1 expression, which suggests that ect- 1 might be glucose-sensitive [49]. On the other hand, the miR-126 is down-regulated by hyperglycemia/vascular inflammation, as evidenced by proinflammatory cytokine TNF $\alpha$, elevated leukocyte count and fibrinogen levels [49].

The evidence reviewed above indicate that inflammation is a characteristic feature of T2DM and should be considered while designing further studies aimed at evaluating the clinical use of miRNAs in T2DM. As it was described above, some miRNAs are down-regulated via pro-inflammatory cytokines, such as $\mathrm{TNFa}$, which was shown to hamper miR-126 expression [49]. High miR-126 expression was found to correlate negatively with markers of vascular inflammation such as leukocyte count, fibrinogen levels, VCAM-1, endothelin and E-selectin. On the other hand, loss of anti-inflammatory miRNAs, including miR-126, increases vascular inflammation in T2DM, as evidenced by elevated leukocyte count and fibrinogen. As a result of VCAM1 $3^{\prime} \mathrm{UTR}$ being directly targeted by miR-126, increased adhesion 
and transmigration of peripheral blood mononuclear cells takes place [49]. Once again, the involvement of miR-126 emerges as promising in T2DM [47, 48], however abnormal expression of miR-146a, miR-103b and miR-21 was also linked to inflammatory response and T2DM [44, 45, 47].

\section{MicroRNA studies linked with T2DM-associated vascular complications}

Endothelial damage is well recognized in T2DM and defined as an imbalance in the production of vasodilator and vasoconstricting factors, predisposing the vasculature towards pro-thrombotic and pro-atherogenic effects [51]. Together with the evidence of hyperglycemia- and inflammation-induced abnormal platelet function, insights into endothelial dysfunction lead to a hypothesis of the etiology and pathogenesis of T2DM and its complications [52]. In fact, platelets are crucial in maintenance of appropriate vascular integrity. These cellular components are known to support the function of vascular endothelium, encourage growth of endothelial cells and release molecules, which improve endothelial barrier function. In response to inflammation, up-regulation of fibrinogen causes recruitment of inflammatory cells and platelets, as well as activation of endothelial cells, hence contributing to vascular inflammation [53]. Therefore, comprehension of mechanisms of both endothelial and platelet dysfunction, contributing to pathogenesis of T2DM, is deemed necessary to refine the vascular complications, frequently resulting in prothrombotic state [52].

In one of the studies vascular cells-expressed and MPsderived miRNAs were investigated to determine their potential contribution to the pathogenesis of vascular complications in T2DM subjects and non-T2DM controls [54]. The expression profile of miR-26a and miR-126 differed significantly between patients with and without T2DM. Both miRNAs were found to be down-regulated in T2DM patients compared to controls. Interestingly, patients with down-regulated miR-26a and miR-126 were more likely to suffer from concomitant coronary artery disease (CAD), but not other comorbidities. Moreover, the authors demonstrated that the miRNAs were abundantly sourced from endothelial cells and by conducting further in vitro experiments, showed that high blood glucose levels contribute to diminished packaging of miR126 and miR-26a into endothelial MPs. The study reveals that the expression profile of endothelial MPs-derived miRNAs is affected by T2DM and might be used to estimate the risk of potential vascular complications in this population [54].

Moreover, Deng et al. [55] evaluated the expression pattern of blood plasma-derived circulating miR-24 and its target YKL-40, which is an inflammatory molecule known to play an important role in endothelial dysfunction, in CHD patients, T2DM-CHD patients and controls. MiR-24 was significantly down-regulated in T2DM-CHD patients in contrast to control subjects. What is more, the expression of YKL-40 mRNA was remarkably increased in both T2DM-CHD and CHD patients vs. controls; as well as significantly higher in T2DM-CHD subjects compared to CHD subjects alone. The investigation of miR24 as a potential biomarker was further analyzed with the help of ROC curve, which demonstrated significant ability to differentiate T2DM-CHD from CHD subjects and controls with an area under the curve (AUC) of 0.975, as well as discriminate T2DM-CHD from CHD subjects with an AUC of 0.953. These findings suggest that circulating miR-24 emerges as a potent regulator of YKL-40 and dynamic biomarker in predicting T2DM and development of cardiovascular complications [55].

Plasma miR-126 and miR-210 were also evaluated in the context of potential association between the miRNAs, T2DM and vascular complications in T2DM patients and healthy controls [56]. The expression of miR-126 was significantly reduced in T2DM subjects with and without CAD, respectively, in contrast to healthy controls. Interestingly, patients with CAD had lower expression of miR-126 compared to patients without CAD. On the other hand, miR-210 was significantly up-regulated by in T2DM subjects with and without CAD, respectively, in contrast to controls, as well as and in patients with CAD in contrast to those without CAD. It is worth noticing that in subjects with CAD, the levels of both miRNAs correlated with glycemia, HbA1c and lipid profile. Furthermore, the ROC curves revealed that plasma miR126 and miR-210 significantly differentiated T2DM with CAD from T2DM without CAD. Overall, plasma miR126 and miR-210 levels could be considered as epigenetic biomarkers for T2DM and vascular complications, especially CAD [56].

Most recently, angiogenic potential of ectosomederived miRNAs was assessed among T2DM patients and controls [57]. The authors reported that 10 miRNAs (miR-20a-3p, miR-26a-5p, miR-26b-5p, miR-29a-5p, miR-374a-5p, miR-30b-5p, miR-30c-5p, let-7i-5p, miR199a-3p, miR-221-3p) were found exclusively in ectosomes obtained from T2DM patients, as determined by low-density qPCR array. Moreover, it was revealed that the expression of both miR-193b-3p and miR-95-3p in the ectosomes-enriched plasma was significantly higher in T2DM, whereas the expression of miR-409-3p expression was lower in T2DM. Bioinformatics tools were then applied to determine the pro- and anti-angiogenic potential of these miRNAs. The analysis demonstrated that miRNAs from miR-26 family, as well as miR-221-3p have 
anti-angiogenic effects, while miRNAs from miR-30 family and miR-199a-3p have pro-angiogenic effects. Overall, the findings suggest a characteristic ectosome-specific miRNA content in diabetic population and may partially elucidate the phenomenon of impaired angiogenesis and development of vascular complications in patients with T2DM [57].

The above-mentioned studies showed correlations between various miRNAs, T2DM and vascular abnormalities. Among the others, it is worth mentioning that miR-126 was suggested as the miRNA that differentiates diabetic from non-diabetic populations.

\section{MicroRNA studies linked with platelet reactivity}

Diabetic subjects are known to exhibit increased platelet activity [41, 53, 58]. Among the interrelated variables that contribute to this phenomenon are hyperglycemia, hyperlipidemia, oxidative stress, glycation of platelet membrane proteins, as well as impaired calcium homeostasis that lead to augmented platelet sensitivity to agonists [53]. Moreover, T2DM is often manifested by hypercoagulable state, known to be a result of disturbances in platelet activation, aggregation and lifespan, in addition to the pro-inflammatory state and endothelial dysfunction [12]. Elucidating the exact mechanisms and participating molecules would help identify T2DM patients at risk of cardiovascular complications and facilitate appropriate treatment.

One of the clinical studies evaluating miRNA signatures of platelets in patients with T2DM that are not linked to CAD was conducted by Stratz et al. [59]. MicroRNA was subjected to miRNA profiling, followed by qRT-PCR validation in both T2DM and non-T2DM patients. Contrary to previous reports, no miRNAs were significantly different between the studied groups, neither T2DM vs. non-T2DM, nor CAD vs. no-CAD, in univariate analyses. However, miR-377-5p, miR-628-3p, miR-3137 could be potential stable predictors of group membership. Functional network analysis of predicted targets for the investigated miRNAs suggest potential contribution of T2DM on mRNA processing. In conclusion, no significant differences were found in platelet miRNA expression between the T2DM cohort and controls, nonetheless functional implications of these molecules on mRNA processing can be important in the pathogenesis of T2DM. It is necessary to design and perform further studies to illustrate the functional network and fully elucidate the relations between miRNAs and T2DM [59].

On the other hand, Fejes et al. analyzed the effect of hyperglycemia on the expression of several platelet and circulating miRNAs derived from megakaryocytes (MKs) in T2DM obese patients, non-T2DM obese patients and healthy individuals [50]. Real-time PCR was used to quantify miRNA, as well as pre-miRNAs and their target mRNA, namely P2RY12 and SELP. It was reported that the expression of mature platelet miR-223, miR26b, miR-140 and miR-126 was lower among T2DM subjects compared with healthy individuals. Circulating miR-223, miR-26b, miR-140 and miR-126 isolated from blood plasma were down-regulated in T2DM in similar fashion to platelet miRNAs. Furthermore, cell culture studies were performed to evaluate the influence of hyperglycaemia on the expression of miRNAs in MKs and revealed significantly reduced expression in the event of higher blood glucose levels. As far as platelet activation is concerned, significantly higher level of surface P-selectin expression was found in T2DM patients compared to healthy and obese controls, suggesting augmented platelet reactivity in this group. Platelet P2RY12 and SELP mRNA were increased by twofold at elevated platelet activation in contrast to control subjects. To conclude, all found miRNAs (miR-223, miR-26b, miR-126, miR-140) are down-regulated in platelets and MKs of T2DM patients, leading to higher expression of P2RY12 and SELP mRNAs, which in turn bring about changes in platelet functions [60].

Overall, the studies demonstrate that platelet miRNAs could reflect platelet function directly or indirectly, for example through their impact on mRNA processing. Many studies described in previous sections also refer to platelets and show the potential for miRNAs to become an excellent diagnostic tool covering many pathological mechanisms simultaneously. Taking into account the importance of maintaining appropriate platelet function in T2DM patients, who are a group of high cardiovascular risk, miRNAs could help repurpose existing drugs and yield new antiplatelet therapies with significant benefits in these individuals. It is worth mentioning that certain miRNAs are commonly co-expressed in diabetic environment, as evidenced in the studies conducted by Zampetaki et al. and Witkowski et al. [61, 62]. For example, miR-126 was revealed to be co-expressed with miR-19a in uncontrolled T2DM, which leads to modulation of some of the effects of miR-126, including control of VCAM1 and therefore monocyte recruitment and atherogenesis. Thus, rather than focusing on single miRNAs that are involved in T2DM an integrated view should also take into account the expression pattern of multiple miRNAs that reflect the complexity of the epigenetic regulation of vascular homeostasis in T2DM.

MicroRNA studies related to T2DM can be classified according to numerous criteria. Having dissected the complex pathogenesis of T2DM into several processes, we aimed to demonstrate that many mechanisms ought to be taken into account in full elucidation of T2DM and related complications (see Fig. 1). Since miRNAs 


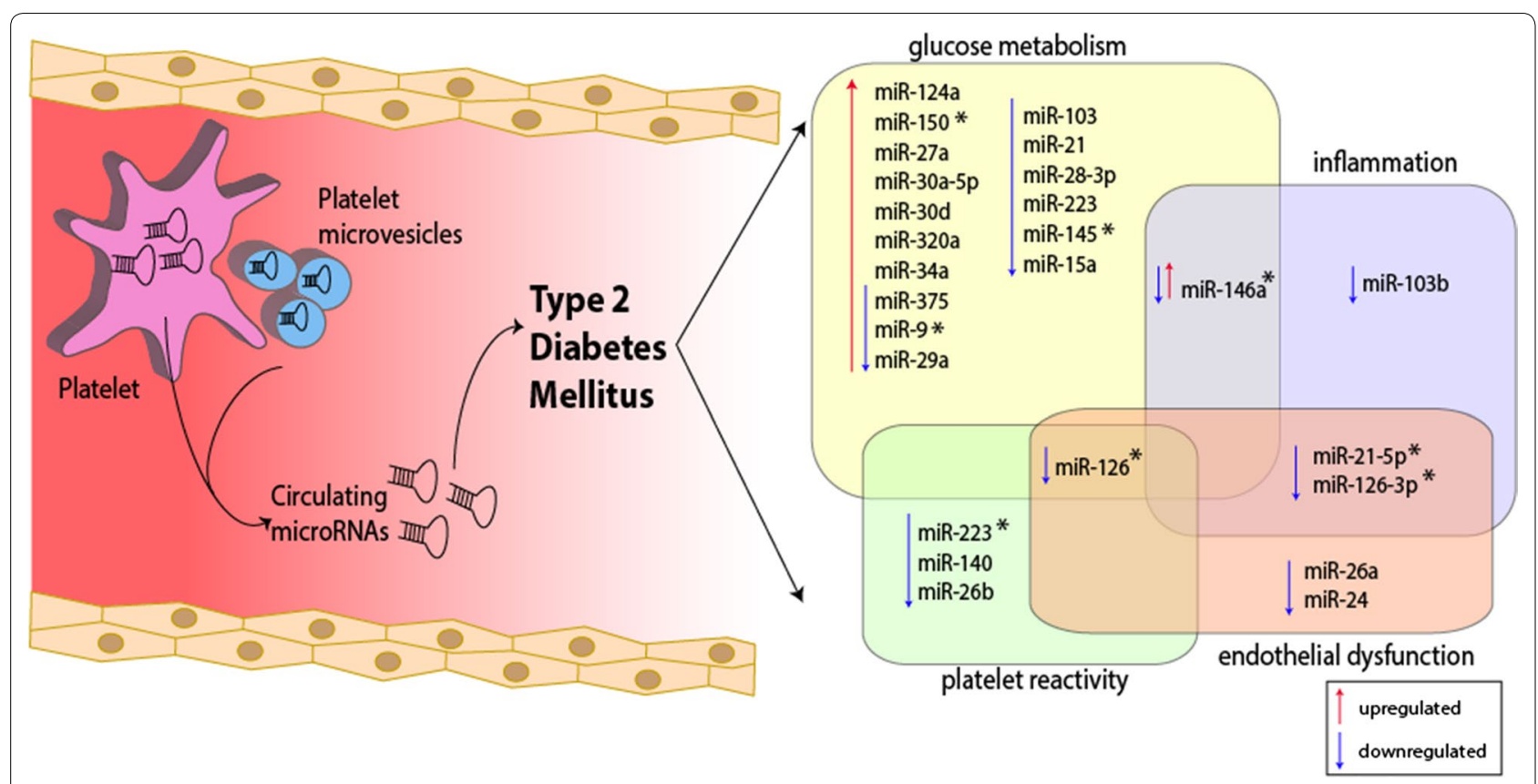

Fig. 1 Regulation of microRNAs serving as T2DM biomarkers based on glucose metabolism, inflammation, platelet reactivity and endothelial dysfunction [36, 63-68]. MiR microRNA. *Endothelium-enrichment miRNAs and miRNAs involved in the regulation of endothelial cell functions

can regulate more than one target gene and exert effects on several levels simultaneously, it is necessary to adopt a holistic approach on all contributing factors. Among the miRNA discussed in this review, miR-126 looks very promising, being the most studied in relation to T2DM. However, circulating levels of miR-126 are also known to the modulated in patients with CAD, acute coronary syndromes, heart failure, as well as by antiplatelet treatment $[63,69-71]$. Hence, any of these conditions could represent a potential cofounder if miR-126 is used in T2DM to predict its future development.

\section{Bioinformatic analysis-miRNA targets predictions, data filtering and visualization as interaction networks}

Coordinated interplay of inflammation, platelet activity, blood coagulation and insulin secretion is implicated in the pathogenesis of T2DM and resulting complications. Our bioinformatics analysis aimed to depict and characterize the miRNAs, which potentially contribute to the pathophysiology of increased platelet reactivity in T2DM through the mentioned mechanisms.

\section{Target prediction}

To identify targets of analyzed miRNAs we used multiMiR 1.4 R package [72]. We searched the top $10 \%$ genes among all conserved and non-conserved target sites in 14 target prediction databases. For input miRNAs without mature version of id's we performed target predictions using all three combinations: stem-loop miRNA and -3p and $-5 p$ versions.

\section{Interaction networks}

MiRNA-target interaction network was constructed in $\mathrm{R}$ and visualized using Cytoscape software v 7 [73]. Genegene interaction data were retrieved from StringApp package version 1.4.2 for Cytoscape. Final networks for genes associated with analyzed processes and pathways were constructed as follows: (1) first we selected all target genes and associated with specific process. (2) Then we subtracted those genes and associated miRNAs as a new process-specific network. (3) From that network we extracted nodes connected with at least 10 other nodes (for gene it was at least 10 other genes, for miRNA at least 10 other targets).

We also performed separated unbiased analysis for all genes and input miRNAs. Due to its complexity we selected nodes with at least 20 neighbors. On all final networks we showed only max top 10 targets and max top 10 miRNAs sorted by the degree of connection. It enabled to retrieve top miRNAs and top shared targets involved in analyzed Gene Ontology (GO) process, we also preformed unbiased analysis on all of the targets of analyzed miRNAs. To construct summary figure we merged all seven of subnetworks containing miRNA-target and target interactions. 


\section{Selection of specific lists of genes}

To identify the genes associated with analyzed processes (platelet activation, blood coagulation, inflammatory response and glucose metabolism) we performed a screening of the GO terms for the presence of the key words using the biomaRt package in R [74]. Key words used for screening the GO terms are available as in our previous paper [17]. For glucose metabolism list, used GO terms were as follows: response to glucose; positive regulation of glucose metabolic process; glucose metabolic process; regulation of glucose metabolic process; glucose mediated signaling pathway; positive regulation of glucose mediated signaling pathway; UDP-glucose metabolic process To retrieve the genes associated with insulin signaling we combined gene lists from KEGG database (hsa04910 Insulin signaling pathway, hsa04930 type II diabetes mellitus, hsa04931 Insulin resistance) and Reactome database (R HSA 422356 Regulation of insulin secretion) $[75,76]$. To retrieve the genes associated with diabetes we combined gene lists from KEGG database (hsa04930 type II diabetes mellitus) and disease query by String Cytoscape plugin for diabetes mellitus type 2 [77]. To retrieve genes associated with hypoglycemia we used results from disease query by String Cytoscape plugin for that term.

\section{Analysis results}

Firstly, we performed interaction network analysis for between the genes associated with specific biological processes and targeting them miRNAs identified based on literature search (see Additional files 2,3). After performing integratory analysis of those results we found that three common miRNAs, namely miR-30a-5p, miR30d-5p and miR-30c-5p might be involved in blood coagulation, platelet activation, glucose metabolism, insulin signaling and inflammation, whereas one common miRNA, miR-320a, could regulate blood coagulation, platelet activation, insulin signaling, as well as inflammatory processes (see Fig. 2). Two common miRNAs-miR-15a-5p and miR-30b-5p-may have an influence on blood coagulation, platelet activation, insulin signaling and glucose metabolism.

To this day, multiple reports on miR-30a-5p have been published in the literature, however only one study showed a link between plasma-circulating miR-30a-5p and T2DM. In line with recent CORDIOPREV trial results, miR-30a-5p was observed to be up-regulated in T2DM subjects compared to healthy controls years before the disease manifested, suggesting its promising role in predicting T2DM occurrence. The baseline plasma levels of circulating miR-30a-5p were increased

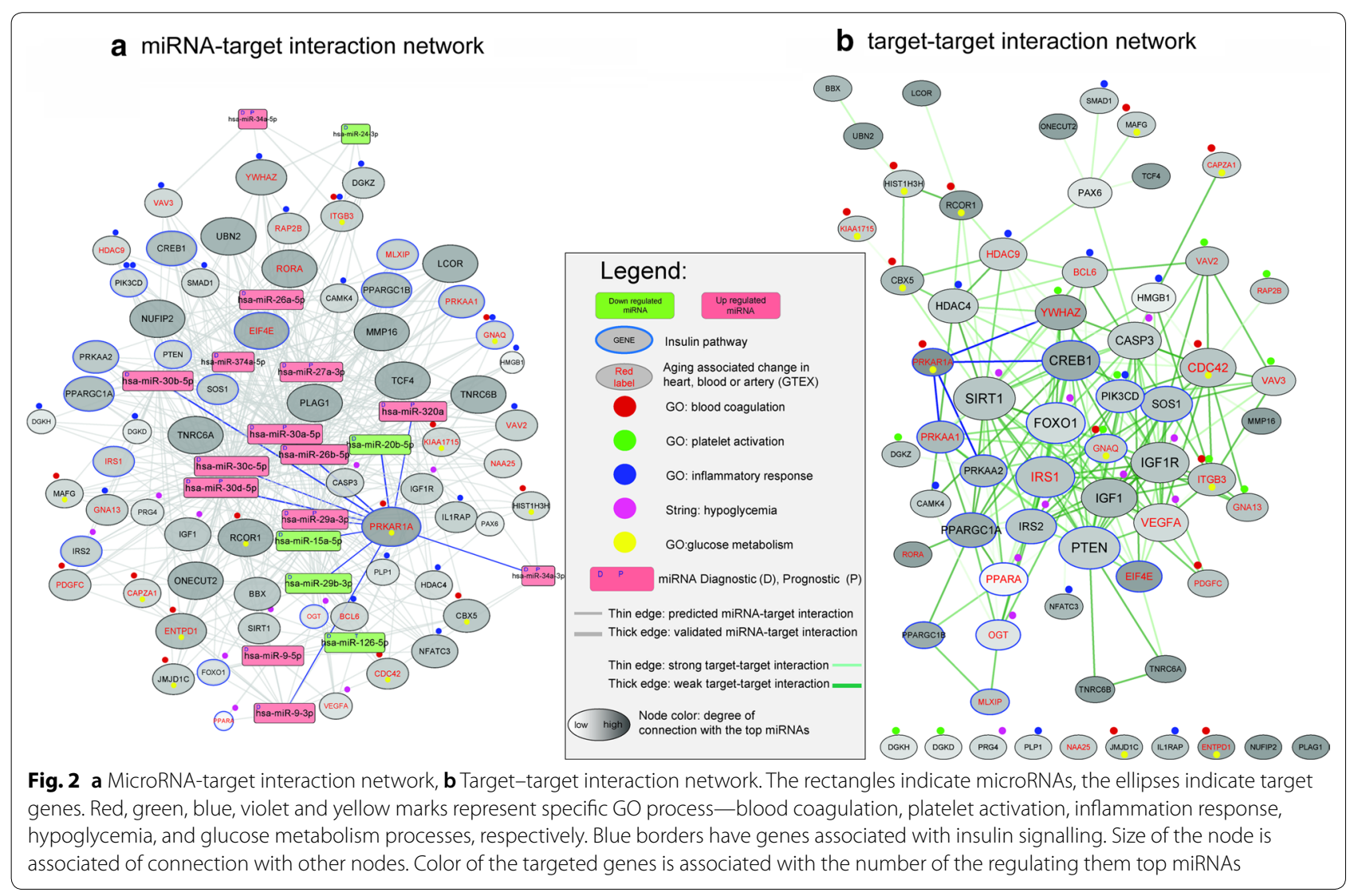


in incident-T2DM subjects in comparison to non-T2DM subjects after a median follow-up of 60 months, with intermediate values in the pre-DM and incident pre-DM patients. This study revealed that plasma miR-30a-5p, as well as miR-150, miR-15a and miR-375, are deregulated before the onset of T2DM and should be further explored as novel biomarkers [35]. MiRNA-30a-5p was also up-regulated in the sera of children with newly diagnosed type 1 diabetes mellitus in a study conducted by Nielsen et al. [78]. Finally, in vitro models demonstrated that miR-30a-5p is involved in glucotoxicity-induced beta-cell dysfunction in rodents [79]. Even though these findings have not been confirmed in human studies yet, the above-mentioned findings indicate that miR-30a-5p should be investigated in greater depth in order to elucidate its links with diabetes.

MiR-30d-5p was described so far in two studies related to T2DM. Delic et al. found that miR-30d-5p was down-regulated in urinary exosomes of microalbuminuric T2DM nephropathy patients in comparison to T2DM patients without nephropathy and healthy controls. According to the authors, lower expression of miR$30 \mathrm{~d}-5 \mathrm{p}$ is required for TGF- $\beta$ apoptosis in podocytes, which further leads to T2DM nephropathy changes [80]. In line with it, Jiang et al. reported that high D-glucose treatment decreased the viability of human AC16 cardiac cells, whereas the treatment with naringenin, a flavonoid extracted from grapefruit as well as other fruits and herbs, diminished this effect through up-regulation of miRNA-30d-5p [81]. MicroRNA microarray screening revealed that the expression of serum miR-30d-5p was significantly lower in T2DM cardiomyopathy patients in comparison to healthy controls. Cardioprotective features of naringenin and the role of miR-30d-5p in this process were further confirmed during transfection of AC16 cardiac cells with miR-30d-5p inhibitor before cotreatment with naringenin, which resulted in decreased viability of AC16 cardiac cells comparing with naringenin and high glucose cohort. The results suggested that miR$30 \mathrm{~d}-5 \mathrm{p}$ is involved in naringenin-induced cytoprotection against high glucose-induced AC16 cardiac cells injury [81]. The described studies focus on T2DM complications rather the disease itself, however they show that miR-30d-5p deserves more attention in the next studies investigating the miRNA profile of T2DM patients. Pancreas-enriched miR-30d was also significantly up-regulated in the plasma of T2DM patients vs. healthy subjects suggesting, that miR-30d might be involved in insulin regulation processes [82]. Interestingly, miR-30d family was also revealed to be involved in systemic inflammatory response syndrome pathophysiology. It was shown to correlate positively with peroxiredoxin-1 ( $\operatorname{Prdx}-1)$, which is secreted by immune cells during inflammation and inversely correlate with pro-inflammatory cytokines (IL-1, IL-6, IL-8, C-reactive protein) [83, 84]. Moreover, miR-30d-5p was also released by in vitro activated immune cells, which further strengthens its role in inflammatory regulation [83].

The role of miR-30c-5p has been previously described in two studies linked to diabetic diseases. Stepien et al. analyzed the levels of miR-30c-5p, among other miRNAs, between blood-derived ectosomes from 15 patients with T2DM and 15 healthy controls, and assessed their angiogenic potential. It was found that the expression of miR-30c-5p ( $\mathrm{p}=0.055)$, miR-20a-3p $(\mathrm{p}=0.064)$ and miR-26a-5p $(p=0.075)$ had a tendency to increase in the ectosomes-enriched plasma of T2DM patients vs. that of control subjects. The authors also stressed the pro-angiogenic effect exerted by the miR-30 family, which could be investigated and applied in clinical practice to monitor cardiovascular complications among T2DM patients [57]. Another study aimed to explore the miRNAs expression profiles in fetal tissues of gestational diabetes mellitus (GDM) patients and normoglycaemic controls. It revealed that seven miRNAs, including miR-30c-5p, miR-452-5p, miR-126-3p, miR-130b-3p, miR-148a-3p, miR-let-7a-5p and miR-let-7g-5p, were up-regulated in the human umbilical vein endothelial cells of infants of GDM patients in comparison to controls [85].

Furthermore, in our analysis we revealed the most significant gene targeted by miRNAs linked to glucose metabolism, blood coagulation and insulin signalling, namely PRKAR1A (protein kinase cAMP-dependent type I regulatory subunit alpha). This gene provides instructions for production of a regulatory, type 1 alpha subunit of protein kinase A (PKA), an enzyme which promotes cell growth and proliferation [86]. Interestingly, Hussain et al. demonstrated the influence of PRKAR1A on the regulation of PKA-mediated pancreatic beta-cell insulin secretion. PRKAR1A ablation and PKA disinhibition in beta-cells in mice increased glucose-dependent insulin secretion. Furthermore, inactivating PRKAR1A mutations (Carney's complex) in humans also resulted in oral glucose tolerance test increased insulin excursions, while plasma glucose excursion were alleviated in comparison to control subjects with similar medical history but without PRKAR1A mutations. The authors stressed that the humans are heterozygotes and the glucose tolerance tests were via oral administration as opposed to the intravenous administration in homozygous $\Delta$-prkarla mice. These differences could clarify the subtle phenotype in humans as compared to $\Delta$-prkarla mice [87]. Gene-gene interaction network analysis showed that PRKAR1A is interacting with four genes which are targets of the top miRNAs. Three of them (CREB1, PRKAA1, PRKAA2) are associated with insulin resistance (KEGG pathway 
hsa04931) and one (YWHAZ) was found as a top gene in platelet activation network (see Additional file 3).

\section{Conclusions}

The increasing prevalence rates of T2DM and its complications impose serious health burden worldwide. Numerous risk factors of T2DM, silent progression of the disease until the emergence of micro- and macrovascular complications and insufficient results of the common therapies call for an urgent need to develop effective methods of early detection, new efficient therapies and prevention measures for the control of T2DM. Hypercoagulable state and the atherothrombotic sequelae are among the most important concerns in modern management of T2DM and its complications.

Since platelets are unquestionably involved in atherosclerosis, it is essential to discover their molecular background and links with T2DM. Importantly, platelets play a significant role in coordinating inflammatory and immune responses. Whereas increased platelet activity helps the organism fight infections, uncontrolled activity might result in inflammation-mediated tissue damage, as observed in T2DM [13]. Furthermore, hyperglycemia and defective glucose metabolism observed in T2DM are known to impair endothelial and platelet function, which in turn contribute to development of vascular complications and prothrombotic state [52, 88]. Cumulatively, these mechanisms provide evidence that hyperglycemiarelated platelet dysfunction, as well as inflammation, might underpin the fact that diabetics are prone to developing CVDs and hence are at risk of increased morbidity and mortality. Platelets therefore are fine cellular indicators of the co-occurrence of T2DM and cardiovascular complications.

The sourceful content of miRNAs in platelets, their biochemical stability in bodily fluids, as well as relative tissue specificity indicate that they might become powerful, non-invasive biomarkers of T2DM and platelet function. The evidence of a large redundancy among the targets of the miRNAs that are modulated in T2DM is worth a comment. In fact, this is a common finding for microRNAs that exert their function as fine modulators of gene expression and work in the form of epigenetic regulation networks where multiple miRNAs contribute to multiple targets genes. Detailed analysis of regulatory networks has important clinical implications. Not only does it provide the research community with reliable information but it also represent the basis to build up complex interaction models to be used in the next future to deliver a personalized approach to diagnosis and treatment. In fact, miRNA profiling of individual patients might be analysed in the bioinformatic model to improve both diagnostic and therapeutic efficiency, especially for chronic and degenerative diseases, where the paradigm one gene, one protein, one disease does not reflect the actual pathophysiology. The studies described in this review demonstrate that various miRNA differentiate T2DM from healthy state, however we observed a discrepancy between miRNAs evaluated by researchers so far and miRNAs obtained as a result of our bioinformatic analysis. For example, miR-126, which has been investigated in most reports included in this manuscript was not deemed significant enough in the analysis. The inconsistent findings may be partly due to differences in demographic characteristics between study populations, small size of study populations and the fact that frequently more focus is placed on one pathological mechanism of T2DM, rather than a combination of several factors. Furthermore, bias in the clinical studies measuring miRNA expression may be related to the study population (T2DM vs. uncontrolled T2DM). The duration of the disease and the extend of vascular inflammation/ complications certainly impacts the epigenetic environment as well). It is worth noticing that up to this day, few studies directly investigated platelet-derived miRNAs in the context of T2DM, however the involvement of platelets in many processes leading to T2DM and related complications provides a promising area for research and potential clinical application.

In this review, we described the methods currently used to detect and investigate miRNAs and summarized the studies on miRNAs in T2DM published so far. Through the application of bioinformatic analysis tools, we associated key biological function and signaling pathways related to the miRNAs with the most prominent differential expression pattern in T2DM compared to controls. Using this approach, we found three common miRNAs, namely miR-30a-5p, miR-30d-5p and miR$30 c-5 p$ as the miRNAs involved in blood coagulation, platelet activation, glucose metabolism, insulin signalling and inflammation. Additionally, results of the bioinformatics analysis demonstrate that PRKAR1A could be one of the most significant gene targeted by miRNAs in T2DM.

\section{Supplementary information}

Supplementary information accompanies this paper at https://doi. org/10.1186/s12933-019-0918-x

Additional file 1. Additional characteristics of microRNA studies in T2DM.

Additional file 2. MicroRNA-target gene networks a) Glucose metabolism miRNA-target gene network b) Blood coagulation miRNA-target gene network c) Hypoglycemia miRNA-target gene network d) Inflammatory response miRNA-target gene network. The rectangles indicate microRNAs, the ellipses indicate target genes. Red, green, blue, violet and yellow marks represent specific GO process-blood coagulation, platelet activation, inflammation response, hypoglycemia, and glucose metabolism 
processes, respectively. Blue borders have genes associated with insulin signalling. Top 4 targets are highlighted from each network with colored edges.

Additional file 3. MicroRNA-target gene networks. a) Insulin metabolism miRNA-target gene network. b) Platelet activation miRNA-target gene network. c) Top-unbiased. top ten gene targeted by top ten miRNAs sorted by the degree of connection. The rectangles indicate microRNAs, the ellipses indicate target genes. Red, green, blue, violet and yellow marks represent specific GO process - blood coagulation, platelet activation, inflammation response, hypoglycemia, and glucose metabolism processes, respectively. Blue borders have genes associated with insulin signalling. Top 4 targets are highlighted from each network with colored edges.

\section{Abbreviations}

T2DM: type 2 diabetes mellitus; CVD: cardiovascular disease; MPs: microparticles; miRNAs: microRNAs; qRT-PCR: quantitative reverse transcription polymerase chain reaction; NGS: next-generation sequencing; NGT: normal glucose tolerance; IGT: impaired glucose tolerance; IFG: impaired fasting glucose; ROC: receiver operator characteristic; $\mathrm{HbA} 1 \mathrm{c}$ : glycated hemoglobin; TNFs: tumour necrosis factors; IL-6: interleukin-6; NFK $\beta$ : nuclear factor KB; mRNA: messenger RNA; FBG: fasting blood glucose; SFRP4: secreted frizzled-related protein 4; CHD: coronary heart disease; T2DM NC: T2DM subjects without complications; T2DM C: T2DM subjects with complications; MACE: major cardiovascular events; VCAM-1: vascular cell adhesion protein-1; TF: tissue factor; CAD: coronary artery disease; AUC: area under the curve; MKs: megakaryocytes; GO: Gene Ontology; Prdx-1: peroxiredoxin-1; GDM: gestational diabetes mellitus; PRKAR1A: protein kinase CAMP-dependent type I regulatory subunit alpha; PKA: protein kinase $A$.

\section{Acknowledgements}

Not applicable.

\section{Authors' contributions}

JP, DJ, JJP, PC, SDR, MP: substantial contribution to concept and design, critical writing or revising the intellectual content. CE, SDR, Cl, JSM, MP: edition of the manuscript, supervision of the work. ZW: interpretation of data, bioinformatic analysis. CE: valuable contribution to graphic design. JP, SDR, JSM, MP: critical revision of the article. All the authors: collection, analysis and interpretation of data; verification of analytical methods, final approval of the version to be published. All authors agreed to be accountable for all aspects of the work in ensuring that questions related to the accuracy or integrity of any part of the work are appropriately investigated and resolved. All authors read and approved the final manuscript.

\section{Funding}

This work was supported financially as part of the research grant 'The Diamond Grant 2016' from the Polish Ministry of Science and Higher Education (Grant number 0072/DIA/2017/46) and internal funding of the Department of Experimental and Clinical Pharmacology, Medical University of Warsaw, Centre for Preclinical Research and Technology CEPT, Warsaw, Poland.

\section{Availability of data and materials}

Not applicable.

\section{Ethics approval and consent to participate}

Not applicable.

\section{Consent for publication}

Not applicable.

\section{Competing interests}

The authors declare that they have no competing interests.

\section{Author details}

1 Department of Experimental and Clinical Pharmacology, Center for Preclinical Research and Technology CEPT, Medical University of Warsaw, Banacha 1 B str., 02-097 Warsaw, Poland. ${ }^{2}$ Rheumatology Division, Hospital das Clinicas HCFMUSP, University of São Paulo, School of Medicine, Av. Dr. Arnaldo, 455,
Sao Paulo, SP 01246-903, Brazil. ${ }^{3}$ Division of Cardiology, Department of Medical and Surgical Sciences, "Magna Graecia" University, Viale Europa, 88100 Catanzaro, Italy. ${ }^{4}$ Department of Cardiology, Medical University of Vienna, Vienna, Austria.

Received: 14 June 2019 Accepted: 21 August 2019

Published online: 30 August 2019

\section{References}

1. IDF Diabetes Atlas 6th Edition. Brussels: International Diabetes Federation; 2013. https://www.idf.org/e-library/epidemiology-research/diabetes-atlas /19-atlas-6th-edition.html. Accessed 12th December 2018.

2. Zimmet PZ. Diabetes and its drivers: the largest epidemic in human history? Clin Diabetes Endocrinol. 2017;18(3):1. https://doi.org/10.1186/ s40842-016-0039-3.

3. Stumvoll M, Goldstein BJ, van Haeften TW. Type 2 diabetes: principles of pathogenesis and therapy. Lancet. 2005;365(9467):1333-46. https://doi. org/10.1016/s0140-6736(05)61032-x.

4. Zimmet PZ, Magliano DJ, Herman WH, Shaw JE. Diabetes: a 21st century challenge. Lancet Diabetes Endocrinol. 2014;2(1):56-64. https://doi. org/10.1016/S2213-8587(13)70112-8.

5. Vaidya V, Gangan N, Sheehan J. Impact of cardiovascular complications among patients with Type 2 diabetes mellitus: a systematic review. Expert Rev Pharmacoecon Outcomes Res. 2015;15(3):487-97. https://doi. org/10.1586/14737167.2015.1024661.

6. Wu MD, Atkinson TM, Lindner JR. Platelets and von Willebrand factor in atherogenesis. Blood. 2017;129(11):1415-9. https://doi.org/10.1182/ blood-2016-07-692673.

7. Natarajan A, Zaman AG, Marshall SM. Platelet hyperactivity in type 2 diabetes: role of antiplatelet agents. Diabetes Vasc Dis Res. 2008;5:138-44. https://doi.org/10.3132/dvdr.2008.023.

8. Ferroni P, Basili S, Falco A, et al. Platelet activation in type 2 diabetes mellitus. J Thromb Haemost. 2004;2:1282-91. https://doi.org/10.111 1/j.1538-7836.2004.00836.x.

9. Hotamisligil GS, Shargill NS, Spiegelman BM. Adipose expression of tumor necrosis factor-alpha: direct role in obesity-linked insulin resistance. Science. 1993;259(5091):87-91.

10. Xia C, Rao X, Zhong J. Role of T lymphocytes in type 2 diabetes and diabetes-associated inflammation. J Diabetes Res. 2017;2017:6494795. https://doi.org/10.1155/2017/6494795.

11. Nagy B Jr, Csongrádi E, Bhattoa HP, et al. Investigation of Thr715Pro P-selectin gene polymorphism and soluble P-selectin levels in type 2 diabetes mellitus. Thromb Haemost. 2007;98:186-91.

12. Postula M, Kaplon-Cieslicka A, Rosiak M, Kondracka A, Serafin A, Filipiak KJ, Czlonkowski A, Opolski G, Janicki PK. Genetic determinants of platelet reactivity during acetylsalicylic acid therapy in diabetic patients: evaluation of 27 polymorphisms within candidate genes. J Thromb Haemost. 2011;9(11):2291-301. https://doi.org/10.1111/j.1538-7836.2011.04482.x.

13. Kim SJ, Davis RP, Jenne CN. Platelets as modulators of inflammation. Semin Thromb Hemost. 2018;44(2):91-101. https://doi. org/10.1055/s-0037-1607432.

14. Cortez-Espinosa N, Mayoral LP, Perez-Campos E, Cabrera Fuentes HA, Mayoral EP, Martínez-Cruz R, Canseco SP, Andrade GM, Cruz MM, Velasco IG, Cruz PH. Platelets and platelet-derived microvesicles as immune effectors in type 2 diabetes. Curr Vasc Pharmacol. 2017;15(3):207-17. https:// doi.org/10.2174/1570161115666170126130309.

15. Nielsen CT, Østergaard O, Rasmussen NS, Jacobsen S, Heegaard NHH. A review of studies of the proteomes of circulating microparticles: key roles for galectin-3-binding protein-expressing microparticles in vascular diseases and systemic lupus erythematosus. Clin Proteom. 2017;8(14):11. https://doi.org/10.1186/s12014-017-9146-0.

16. Dangwal $S$, Thum T. MicroRNAs in platelet biogenesis and function. Thromb Haemost. 2012;108:599-604. https://doi.org/10.1160/ TH12-03-0211.

17. Eyileten C, Wicik Z, De Rosa S, Mirowska-Guzel D, Soplinska A, Indolfi C, Jastrzebska-Kurkowska I, Czlonkowska A, Postula M. MicroRNAs as diagnostic and prognostic biomarkers in ischemic stroke-a comprehensive review and bioinformatic analysis. Cells. 2018;7(12):249. https://doi. org/10.3390/cells7120249. 
18. Wang Y, Russell I, Chen C. MicroRNA and stem cell regulation. CurrOpin Mol Ther. 2009;11:292-8.

19. Thum T, Condorelli G. Long noncoding RNAs and microRNAs in cardiovascular pathophysiology. Circ Res. 2015;116(4):751-62. https://doi. org/10.1161/CIRCRESAHA.116.303549.

20. Weber JA, Baxter DH, Zhang S, Huang DY, Huang KH, Lee MJ, Galas DJ, Wang K. The microRNA spectrum in 12 body fluids. Clin Chem. 2010;56(11):1733-41. https://doi.org/10.1373/clinchem.2010.147405.

21. Choi JL, Li S, Han JY. Platelet function tests: a review of progresses in clinical application. Biomed Res Int. 2014;2014:456569. https://doi. org/10.1155/2014/456569.

22. Streit S, Michalski CW, Erkan M, Kleeff J, Friess H. Northern blot analysis for detection and quantification of RNA in pancreatic cancer cells and tissues. Nat Protoc. 2009;4(1):37-43. https://doi.org/10.1038/nprot.2008.216.

23. Várallyay E, Burgyán J, Havelda Z. MicroRNA detection by northern blotting using locked nucleic acid probes. Nat Protoc. 2008;3(2):190-6. https ://doi.org/10.1038/nprot.2007.528.

24. Pordzik J, Pisarz K, De Rosa S, Jones AD, Eyileten C, Indolfi C, Malek $\mathrm{L}$, Postula M. The potential role of platelet-related microRNAs in the development of cardiovascular events in high-risk populations, including diabetic patients: a review. Front Endocrinol. 2018;20(9):74. https://doi. org/10.3389/fendo.2018.00074.

25. Ferraro D, Champ J, Teste B, Serra M, Malaquin L, Viovy JL, de Cremoux $P$, Descroix S. Microfluidic platform combining droplets and magnetic tweezers: application to HER2 expression in cancer diagnosis. Sci Rep. 2016;9(6):25540. https://doi.org/10.1038/srep25540.

26. Eminaga S, Christodoulou DC, Vigneault F, Church GM, Seidman JG. Quantification of microRNA expression with next-generation sequencing Curr Protoc Mol Biol. 2013;4(4):17. https://doi.org/10.1002/0471142727 mb0417s103.

27. Chugh P, Dittmer DP. Potential pitfalls in microRNA profiling. Wiley Interdiscip Rev RNA. 2012;3(5):601-16. https://doi.org/10.1002/wrna.1120.

28. De Rosa S, Indolfi C. Circulating microRNAs as biomarkers in cardiovascular diseases. Exp Suppl. 2015;106:139-49. https://doi. org/10.1007/978-3-0348-0955-9_6.

29. Kong L, Zhu J, Han W, Jiang X, Xu M, Zhao Y, Dong Q, Pang Z, Guan Q, Gao L, Zhao J, Zhao L. Significance of serum microRNAs in pre-diabetes and newly diagnosed type 2 diabetes: a clinical study. Acta Diabetol. 2011;48(1):61-9. https://doi.org/10.1007/s00592-010-0226-0.

30. Karolina DS, Tavintharan S, Armugam A, Sepramaniam S, Pek SL, Wong MT, Lim SC, Sum CF, Jeyaseelan K. Circulating miRNA profiles in patients with metabolic syndrome. J Clin Endocrinol Metab. 2012;97(12):E2271-6. https://doi.org/10.1210/jc.2012-1996.

31. Zhang T, Lv C, Li L, Chen S, Liu S, Wang C, Su B. Plasma miR-126 is a potential biomarker for early prediction of type 2 diabetes mellitus in susceptible individuals. Biomed Res Int. 2013;2013:761617. https://doi. org/10.1155/2013/761617.

32. Liu Y, Gao G, Yang C, Zhou K, Shen B, Liang H, Jiang X. The role of circulating microRNA-126 (miR-126): a novel biomarker for screening prediabetes and newly diagnosed type 2 diabetes mellitus. Int J Mol Sci. 2014;15(6):10567-77. https://doi.org/10.3390/ijms150610567.

33. Ghorbani S, Mahdavi R, Alipoor B, Panahi G, Nasli Esfahani E, Razi F, Taghikhani M, Meshkani R. Decreased serum microRNA-21 level is associated with obesity in healthy and type 2 diabetic subjects. Arch Physiol Biochem. 2018;124(4):300-5. https://doi.org/10.1080/13813 455.2017.1396349.

34. Al-Muhtaresh HA, Al-Kafaji G. Evaluation of two-diabetes related microRNAs suitability as earlier blood biomarkers for detecting prediabetes and type 2 diabetes mellitus. J Clin Med. 2018;7(2):12. https://doi.org/10.3390/ jcm7020012.

35. Jiménez-Lucena R, Rangel-Zúñiga OA, Alcalá-Díaz JF, López-Moreno J, Roncero-Ramos I, Molina-Abril H, Yubero-Serrano EM, Caballero-Villarraso J, Delgado-Lista J, Castaño JP, Ordovás JM, Pérez-Martinez P, Camargo A, López-Miranda J. Circulating miRNAs as predictive biomarkers of type 2 diabetes mellitus development in coronary heart disease patients from the CORDIOPREV study. Mol Ther Nucleic Acids. 2018;7(12):146-57. https ://doi.org/10.1016/j.omtn.2018.05.002.

36. Zampetaki A, Kiechl S, Drozdov I, Willeit P, Mayr U, Prokopi M, Mayr A, Weger S, Oberhollenzer F, Bonora E, Shah A, Willeit J, Mayr M. Plasma microRNA profiling reveals loss of endothelial miR-126 and other
microRNAs in type 2 diabetes. Circ Res. 2010;107(6):810-7. https://doi. org/10.1161/CIRCRESAHA. 110.226357.

37. Zhang T, Li L, Shang Q, Lv C, Wang C, Su B. Circulating miR-126 is a potential biomarker to predict the onset of type 2 diabetes mellitus in susceptible individuals. Biochem Biophys Res Commun. 2015;463(1-2):60-3. https://doi.org/10.1016/j.bbrc.2015.05.017.

38. Lontchi-Yimagou E, Sobngwi E, Matsha TE, Kengne AP. Diabetes mellitus and inflammation. Curr Diab Rep. 2013;13(3):435-44. https://doi. org/10.1007/s11892-013-0375-y.

39. Kapłon-Cieślicka A, Postuła M, Rosiak M, Peller M, Kondracka A, Serafin A, Trzepla E, Opolski G, Filipiak KJ. Association of adipokines and inflammatory markers with lipid control in type 2 diabetes. Pol Arch Med Wewn. 2015;125(6):414-23.

40. Postula M, Janicki PK, Eyileten C, Rosiak M, Kaplon-Cieslicka A, Sugino S, Wilimski R, Kosior DA, Opolski G, Filipiak KJ, Mirowska-Guzel D. Nextgeneration re-sequencing of genes involved in increased platelet reactivity in diabetic patients on acetylsalicylic acid. Platelets. 2016;27(4):357-64. https://doi.org/10.3109/09537104.2015.1109071.

41. Rivas Rios JR, Franchi F, Rollini F, Angiolillo DJ. Diabetes and antiplatelet therapy: from bench to bedside. Cardiovasc Diagn Ther. 2018;8(5):594609. https://doi.org/10.21037/cdt.2018.05.09.

42. Calverley DC, Baldermann LV, Moran K, Chen NN, McFann K. Platelet FcgammaRIIA expression is associated with the alpha2 integrin C807T gene polymorphism in type 2 diabetes. Platelets. 2006;17(2):78-83. https ://doi.org/10.1080/09537100500260865.

43. Calverley DC, Brass E, Hacker MR, Tsao-Wei DD, Espina BM, Pullarkat VA, Hodis HN, Groshen S. Potential role of platelet FcgammaRIIA in collagen-mediated platelet activation associated with atherothrombosis. Atherosclerosis. 2002;164(2):261-7.

44. Balasubramanyam M, Aravind S, Gokulakrishnan K, Prabu P, Sathishkumar C, Ranjani H, Mohan V. Impaired miR-146a expression links subclinical inflammation and insulin resistance in type 2 diabetes. Mol Cell Biochem. 2011;351(1-2):197-205. https://doi.org/10.1007/s11010-011-0727-3.

45. Luo M, Li R, Deng X, Ren M, Chen N, Zeng M, Yan K, Xia J, Liu F, Ma W, Yang $Y$, Wan Q, Wu J. Platelet-derived miR-103b as a novel biomarker for the early diagnosis of type 2 diabetes. Acta Diabetol. 2015;52(5):943-9. https ://doi.org/10.1007/s00592-015-0733-0.

46. Mahdi T, Hänzelmann S, Salehi A, Muhammed SJ, Reinbothe TM, Tang Y, Axelsson AS, Zhou Y, Jing X, Almgren P, Krus U, Taneera J, Blom AM, Lyssenko V, Esguerra JL, Hansson O, Eliasson L, Derry J, Zhang E, Wollheim CB, Groop L, Renström E, Rosengren AH. Secreted frizzled-related protein 4 reduces insulin secretion and is overexpressed in type 2 diabetes. Cell Metab. 2012;16(5):625-33. https://doi.org/10.1016/j.cmet.2012.10.009.

47. Olivieri F, Spazzafumo L, Bonafè M, Recchioni R, Prattichizzo F, Marcheselli F, Micolucci L, Mensà E, Giuliani A, Santini G, Gobbi M, Lazzarini R, Boemi M, Testa R, Antonicelli R, Procopio AD, Bonfigli AR. MiR-21-5p and miR126a-3p levels in plasma and circulating angiogenic cells: relationship with type 2 diabetes complications. Oncotarget. 2015;6(34):35372-82. https://doi.org/10.18632/oncotarget.6164.

48. Giannella A, Radu CM, Franco L, Campello E, Simioni P, Avogaro A, de Kreutzenberg SV, Ceolotto G. Circulating levels and characterization of microparticles in patients with different degrees of glucose tolerance. Cardiovasc Diabetol. 2017:16(1):118. https://doi.org/10.1186/s1293 3-017-0600-0.

49. Witkowski M, Weithauser A, Tabaraie T, Steffens D, Kränkel N, Witkowski M, Stratmann B, Tschoepe D, Landmesser U, Rauch-Kroehnert U. MicroRNA-126 reduces the blood thrombogenicity in diabetes mellitus via targeting of tissue factor. Arterioscler Thromb Vasc Biol. 2016;36(6):1263-71. https://doi.org/10.1161/ATVBAHA. 115.306094.

50. Harris TA, Yamakuchi M, Kondo M, Oettgen P, Lowenstein CJ. Ets-1 and Ets-2 regulate the expression of microRNA-126 in endothelial cells. Arterioscler Thromb Vasc Biol. 2010;30(10):1990-7. https://doi.org/10.1161/ ATVBAHA.110.211706.

51. Dhananjayan R, Koundinya KS, Malati T, Kutala VK. Endothelial dysfunction in type 2 diabetes mellitus. Indian J Clin Biochem. 2016;31 (4):372-9. https ://doi.org/10.1007/s12291-015-0516-y.

52. Kaur R, Kaur M, Singh J. Endothelial dysfunction and platelet hyperactivity in type 2 diabetes mellitus: molecular insights and therapeutic strategies. Cardiovasc Diabetol. 2018;17(1):121. https://doi.org/10.1186/s1293 3-018-0763-3. 
53. Jagadapillai R, Rane MJ, Lin X, Roberts AM, Hoyle GW, Cai L, Gozal E. Diabetic microvascular disease and pulmonary fibrosis: the contribution of platelets and systemic inflammation. Int J Mol Sci. 2016;17(11):1853. https ://doi.org/10.3390/ijms17111853.

54. Jansen F, Wang H, Przybilla D, Franklin BS, Dolf A, Pfeifer P, Schmitz T, Flender A, Endl E, Nickenig G, Werner N. Vascular endothelial microparticles-incorporated microRNAs are altered in patients with diabetes mellitus. Cardiovasc Diabetol. 2016;22(15):49. https://doi.org/10.1186/s1293 3-016-0367-8.

55. Deng X, Liu Y, Luo M, Wu J, Ma R, Wan Q, Wu J. Circulating miRNA-24 and its target YKL-40 as potential biomarkers in patients with coronary heart disease and type 2 diabetes mellitus. Oncotarget. 2017;8(38):63038-46. https://doi.org/10.18632/oncotarget.18593.

56. Amr KS, Abdelmawgoud H, Ali ZY, Shehata S, Raslan HM. Potential value of circulating microRNA-126 and microRNA-210 as biomarkers for type 2 diabetes with coronary artery disease. Br J Biomed Sci. 2018;75(2):82-7. https://doi.org/10.1080/09674845.2017.1402404.

57. Stepień Et, Durak-Kozica M, Kamińska A, Targosz-Korecka M, Libera M, Tylko G, Opalińska A, Kapusta M, Solnica B, Georgescu A, Costa MC, Czyżewska-Buczyńska A, Witkiewicz W, Małecki MT, Enguita FJ. Circulating ectosomes: determination of angiogenic microRNAs in type 2 diabetes. Theranostics. 2018;8(14):3874-90. https://doi.org/10.7150/thno.23334.

58. Rollini F, Franchi F, Muñiz-Lozano A, Angiolillo DJ. Platelet function profiles in patients with diabetes mellitus. J Cardiovasc TransI Res. 2013;6(3):32945. https://doi.org/10.1007/s12265-013-9449-0.

59. Stratz C, Nührenberg T, Fiebich BL, Amann M, Kumar A, Binder H, Hoffmann I, Valina C, Hochholzer W, Trenk D, Neumann FJ. Controlled type II diabetes mellitus has no major influence on platelet micro-RNA expression. Results from micro-array profiling in a cohort of 60 patients. Thromb Haemost. 2014;1 11(5):902-11. https://doi.org/10.1160/th13-06-0476.

60. Fejes Z, Póliska S, Czimmerer Z, Káplár M, Penyige A, Gál Szabó G, Beke Debreceni I, Kunapuli SP, Kappelmayer J, Nagy B Jr. Hyperglycaemia suppresses microRNA expression in platelets to increase P2RY12 and SELP levels in type 2 diabetes mellitus. Thromb Haemost. 2017;117(3):529-42. https://doi.org/10.1160/TH16-04-0322.

61. Zampetaki A, Willeit P, Tilling L, Drozdov I, Prokopi M, Renard JM, Mayr A, Weger S, Schett G, Shah A, Boulanger CM, Willeit J, Chowienczyk PJ, Kiechl S, Mayr M. Prospective study on circulating MicroRNAs and risk of myocardial infarction. J Am Coll Cardiol. 2012;60(4):290-9. https://doi. org/10.1016/j.jacc.2012.03.056.

62. Witkowski M, Tabaraie T, Steffens D, Friebel J, Dörner A, Skurk C, Witkowski M, Stratmann B, Tschoepe D, Landmesser U, Rauch U. MicroRNA-19a contributes to the epigenetic regulation of tissue factor in diabetes. Cardiovasc Diabetol. 2018;17(1):34. https://doi.org/10.1186/s12933-018-0678-z.

63. Fichtlscherer S, De Rosa S, Fox H, Schwietz T, Fischer A, Liebetrau C, Weber M, Hamm CW, Röxe T, Müller-Ardogan M, Bonauer A, Zeiher AM, Dimmeler S. Circulating microRNAs in patients with coronary artery disease. Circ Res. 2010;107(5):677-84. https://doi.org/10.1161/CIRCRESAHA.109.21556 6.

64. Zhuang G, Wu X, Jiang Z, Kasman I, Yao J, Guan Y, et al. Tumour-secreted mir-9 promotes endothelial cell migration and angiogenesis by activating the JAK-STAT pathway. EMBO J. 2012;31(17):3513-23. https://doi. org/10.1038/emboj.2012.183.

65. Nicoli S, Standley C, Walker P, Hurlstone A, Fogarty KE, Lawson ND. MicroRNA-mediated integration of haemodynamics and Vegf signalling during angiogenesis. Nature. 2010;464(7292):1196-200. https://doi.org/10.1038/ nature08889.

66. Hergenreider E, Heydt S, Tréguer K, Boettger T, Horrevoets AJ, Zeiher AM, Scheffer MP, Frangakis AS, Yin X, Mayr M, Braun T, Urbich C, Boon RA, Dimmeler $\mathrm{S}$. Atheroprotective communication between endothelial cells and smooth muscle cells through miRNAs. Nat Cell Biol. 2012;14(3):249-56. https://doi.org/10.1038/ncb2441.

67. Vasa-Nicotera M, Chen H, Tucci P, Yang AL, Saintigny G, Menghini R, Mahè C, Agostini M, Knight RA, Melino G, Federici M. miR-146a is modulated in human endothelial cell with aging. Atherosclerosis. 2011;217(2):326-30. https://doi.org/10.1016/j.atherosclerosis.2011.03.034.

68. Cheng HS, Sivachandran N, Lau A, Boudreau E, Zhao JL, Baltimore D, Delgado-Olguin P, Cybulsky MI, Fish JE. MicroRNA-146 represses endothelial activation by inhibiting pro-inflammatory pathways. EMBO Mol Med. 2013;5(7):1017-34. https://doi.org/10.1002/emmm.201202318.
69. De Rosa S, Fichtlscherer S, Lehmann R, Assmus B, Dimmeler S, Zeiher AM. Transcoronary concentration gradients of circulating microRNAs. Circulation. 2011;124(18):1936-44. https://doi.org/10.1161/CIRCULATIO NAHA.111.037572.

70. De Rosa S, Eposito F, Carella C, Strangio A, Ammirati G, Sabatino J, Abbate FG, laconetti C, Liguori V, Pergola V, Polimeni A, Coletta S, Gareri C, Trimarco B, Stabile G, Curcio A, Indolfi C, Rapacciuolo A. Transcoronary concentration gradients of circulating microRNAs in heart failure. Eur J Heart Fail. 2018;20(6):1000-10. https://doi.org/10.1002/ejhf.1119.

71. Carino A, De Rosa S, Sorrentino S, Polimeni A, Sabatino J, Caiazzo G, Torella D, Spaccarotella C, Mongiardo A, Strangio A, Filippis C, Indolfi C. Modulation of circulating MicroRNAs levels during the switch from clopidogrel to ticagrelor. Biomed Res Int. 2016;2016:3968206. https://doi. org/10.1155/2016/3968206.

72. RuY, Kechris KJ, Tabakoff B, Hoffman P, Radcliffe RA, Bowler R, Mahaffey S, Rossi S, Calin GA, Bemis L, Theodorescu D. The multiMiR R package and database: integration of microRNA-target interactions along with their disease and drug associations. Nucleic Acids Res. 2014;42(17):e133. https ://doi.org/10.1093/nar/gku631.

73. Shannon P, Markiel A, Ozier O, Baliga NS, Wang JT, Ramage D, Amin N, Schwikowski B, Ideker T. Cytoscape: a software environment for integrated models of biomolecular interaction networks. Genome Res. 2003;13(11):2498-504. https://doi.org/10.1101/gr.1239303.

74. Durinck S, Spellman PT, Birney E, Huber W. Mapping identifiers for the integration of genomic datasets with the R/Bioconductor package biomaRt. Nat Protoc. 2009;4(8):1 184-91. https://doi.org/10.1038/nprot .2009.97.

75. Kanehisa M, Furumichi M, Tanabe M, Sato Y, Morishima K. KEGG: new perspectives on genomes, pathways, diseases and drugs. Nucleic Acids Res. 2017;45(D1):D353-61. https://doi.org/10.1093/nar/gkw1092.

76. Fabregat A, Jupe S, Matthews L, Sidiropoulos K, Gillespie M, Garapati P, Haw R, Jassal B, Korninger F, May B, Milacic M, Roca CD, Rothfels K, Sevilla C, Shamovsky V, Shorser S, Varusai T, Viteri G, Weiser J, Wu G, Stein L, Hermjakob H, D'Eustachio P. The reactome pathway knowledgebase. Nucleic Acids Res. 2018;46(D1):D649-55. https://doi.org/10.1093/nar/gkx1132.

77. Doncheva NT, Morris J, Gorodkin J, Jensen LJ. Cytoscape stringApp: network analysis and visualization of proteomics data. J Proteome Res. 2018. https://doi.org/10.1021/acs.jproteome.8b00702.

78. Nielsen LB, Wang C, Sørensen K, Bang-Berthelsen CH, Hansen L, Andersen ML, Hougaard P, Juul A, Zhang CY, Pociot F, Mortensen HB. Circulating levels of microRNA from children with newly diagnosed type 1 diabetes and healthy controls: evidence that miR-25 associates to residual beta-cell function and glycaemic control during disease progression. Exp Diabetes Res. 2012;2012:896362. https://doi.org/10.1155/2012/896362.

79. Kim JW, You YH, Jung S, Suh-Kim H, Lee IK, Cho JH, Yoon KH. miRNA$30 a-5 p$-mediated silencing of Beta2/NeuroD expression is an important initial event of glucotoxicity-induced beta cell dysfunction in rodent models. Diabetologia. 2013;56(4):847-55. https://doi.org/10.1007/s0012 5-012-2812-x.

80. Delić D, Eisele C, Schmid R, Baum P, Wiech F, Gerl M, Zimdahl H, Pullen SS, Urquhart R. Urinary exosomal miRNA signature in type ii diabetic nephropathy patients. PLoS ONE. 2016;11(3):e0150154. https://doi. org/10.1371/journal.pone.0150154.

81. Jiang J, Liang G, Wu Z, Mo H, You W, Wang Z, Wu K, Guo R. Naringenin alleviates high $D$-glucose-induced injuries through up-regulation of microRNA-30d-5p level in human AC16 cardiac cells. J Appl Biomed. 2018;16:274-80. https://doi.org/10.1016/j.jab.2018.02.005.

82. Seyhan AA, Nunez Lopez YO, Xie H, Yi F, Mathews C, Pasarica M, Pratley RE. Pancreas-enriched miRNAs are altered in the circulation of subjects with diabetes: a pilot cross-sectional study. Sci Rep. 2016;25(6):31479. https:// doi.org/10.1038/srep31479.

83. Caserta S, Mengozzi M, Kern F, Newbury SF, Ghezzi P, Llewelyn MJ. Severity of systemic inflammatory response syndrome affects the blood levels of circulating inflammatory-relevant MicroRNAs. Front Immunol. 2018;5(8):1977. https://doi.org/10.3389/fimmu.2017.01977.

84. Caserta S, Kern F, Cohen J, Drage S, Newbury SF, Llewelyn MJ. Circulating plasma microRNAs can differentiate human sepsis and systemic inflammatory response syndrome (SIRS). Sci Rep. 2016;6:28006. https://doi. org/10.1038/srep28006.

85. Tryggestad JB, Vishwanath A, Jiang S, Mallappa A, Teague AM, Takahashi $Y$, Thompson DM, Chernausek SD. Influence of gestational diabetes 
mellitus on human umbilical vein endothelial cell miRNA. Clin Sci. 2016;130(21):1955-67. https://doi.org/10.1042/CS20160305.

86. Genetics Home Reference. https://ghr.nlm.nih.gov/gene/PRKAR1A. Accessed 3 Mar 2019.

87. Hussain MA, Stratakis C, Kirschner L. Prkar1a in the regulation of insulin secretion. Horm Metab Res. 2012;44(10):759-65. https://doi. org/10.1055/s-0032-1321866.

88. Santilli F, Simeone P, Liani R, Davì G. Platelets and diabetes mellitus. Prostaglandins Other Lipid Mediat. 2015;120:28-39. https://doi.org/10.1016/j. prostaglandins.2015.05.002.

\section{Publisher's Note}

Springer Nature remains neutral with regard to jurisdictional claims in published maps and institutional affiliations.
Ready to submit your research? Choose BMC and benefit from:

- fast, convenient online submission

- thorough peer review by experienced researchers in your field

- rapid publication on acceptance

- support for research data, including large and complex data types

- gold Open Access which fosters wider collaboration and increased citations

- maximum visibility for your research: over 100M website views per year

At BMC, research is always in progress.

Learn more biomedcentral.com/submissions 